\title{
Creep of Annealed and Cold-Drawn High-Purity Copper
}

\author{
William D. Jenkins and Thomas G. Digges
}

\begin{abstract}
A study was made of the effect of temperature and stress on the creep behavior at $110^{\circ}, 250^{\circ}$, and $300^{\circ} \mathrm{F}$ of high-purity oxygen-free high-conductivity copper initially as annealed and as cold-drawn 40-percent reduction of area. The resistance to creep and to fracture at all these test temperatures was increased by cold-drawing the copper prior to testing in creep; however, this superiority in creep properties was accompanied by a decrease in ductility and time to rupture. Dissociation of parent grains into crystals of microscopic dimensions and the presence of strain markings were evidenced in all specimens carried to complete fracture in creep. Correlations are made of these changes in structure with time, stress, temperature, and the discontinuous flow, as evidenced by the creep rateextension curves.
\end{abstract}

\section{Introduction}

The results of creep tests made at different temperatures on annealed high-purity (OFHC) copper were described in a recent paper [1]. ${ }^{1}$ It was found that the strain rate in the second stage was not constant, and the formation of cracks of microscopic dimensions often accompanied but was not necessarily a prerequisite for the initiation of the third stage of creep in this material. Furthermore, the original grains of the annealed copper broke down into subsize grains under varying test conditions, and strain markings were present in all specimens fractured in creep. As a part of a continuing study of the creep behavior of high-purity metals and binary alloys, additional creep tests have been completed on specimens prepared from this same lot of copper in the initial conditions both as annealed and as cold-drawn 40-percent reduction in area. The creep tests were made at different strain rates and at temperatures of $110^{\circ}, 250^{\circ}$, and $300^{\circ} \mathrm{F}$. The creep tests were supplemented by hardness and tensile tests at room temperature and by a metallographic examination of specimens representative of the initial conditions of the copper and of the different stages of creep and fracture. These results are summarized in the present report.

\section{Material and Testing Procedures}

Some of the properties at room temperature of the high-purity copper $(99.99+\%$ of copper $)$ in the initial conditions as annealed and as colddrawn 40-percent reduction in area are given in table 1 .

All specimens of the annealed material were prepared from the same bar as that used previously [1], and the test specimens of the cold-drawn copper were prepared from another bar, originally from the same heat. The testing procedures and apparatus have been already described in some detail $[1,2]$. Essentially, the creep specimens were machined to 0.505 -in. diameter and 2.0-in. gage length. Each specimen was held at a test temperature of $110^{\circ}, 250^{\circ}$, or $300^{\circ} \mathrm{F}$ for $48 \mathrm{hrs}$ before loading to the

\footnotetext{
${ }^{1}$ Figures in brackets indicate the literature references at the end of this paper.
}

desired creep stress at a controlled rate of $3,200^{2}$ $\mathrm{psi} / \mathrm{hr}$ for the annealed and 5,333 psi for the colddrawn specimens $(3,200$ or 5,333 psi odded at $1-\mathrm{hr}$ intervals); each creep test was made at a constant load. The temperatures of the creep furnaces were controlled within the range of about $\pm 1^{\circ} \mathrm{F}$ of the desired temperatures, and the probable error in measuring the extensions was less than 0.00002 in.

TABLE 1. Grain size and mechanical properties at room temperature of the copper used

[The tensile tests were made at a rate of extension of approximately 1 percent per minute]

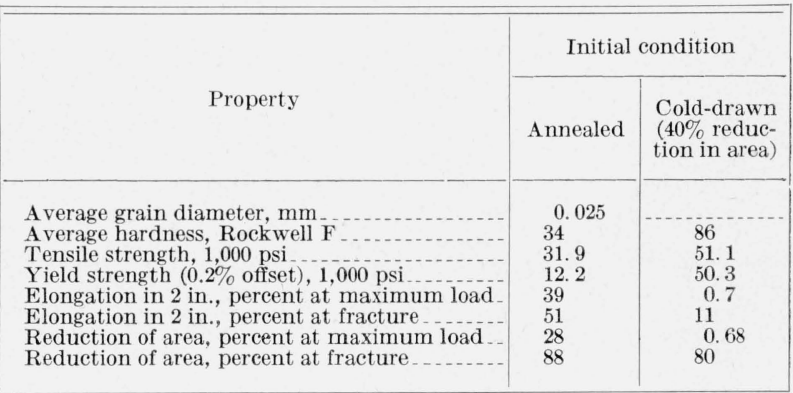

Hardness tests were made at room temperature on all specimens fractured in creep. Two flats $180^{\circ}$ apart were prepared parallel to the longitudinal axis of the specimen after fracturing and Rockwell readings ( $\mathrm{F}$ scale, $60-\mathrm{kg}$ load, 1/16-in. diameter ball) were made at various points along the center line of these flats. Metallographic examinations were made of specimens representative of the copper as annealed, cold-drawn, and deformed in creep.

\section{Results and Discussion}

\subsection{Influence of Temperature, Stress, and Rate of Loading of Creep Behavior}

The resistance to flow of the cold-drawn copper decreased as the test temperature was increased

2 A rate of loading of $3,200 \mathrm{psi} / \mathrm{hr}$ (a load of 3,200 psi, added at 1-hr intervals) was selected as a standard rate for the annealed copper previously tested in creep 11]. As the area of an annealed specimen is reduced to three-fifths of its original
area by cold-drawing 40-percent reduction of area, the cold-drawn specimens were loaded in intervals of $3,200 \times 5 / 3=5,333$ psi. 
(fig. 1); the stress-strain curves for specimens tested at $250^{\circ}$ and $300^{\circ} \mathrm{F}$ were nearly alike for stresses ranging up to about 15,000 psi.

Extension-time curves for specimens prepared from cold-drawn copper and annealed copper are given in figures 2 to 6 .

It is a common belief that the extension at fracture of a metal or alloy tested in creep usually increases as the time to initiate each stage and to fracture decreases. However, with the high-purity copper, the extension-time relationship varied depending upon the test conditions (temperature, strain rate, history, etc.) For example, with the initially colddrawn copper at $110^{\circ} \mathrm{F}$, two specimens (fig. 2, tests 4 and 3 ) had the same extension at fractures, but the times to fracture were 28 and $236 \mathrm{hr}$, respectively. At $250^{\circ} \mathrm{F}$ (fig. 3), the extension in two specimens increased as the time to fracture increased (tests 8 and 7 ), and then the extension in another specimen decreased with a further increase in time to fracture (tests 7 and 6 ). At $300^{\circ} \mathrm{F}$ (fig. 4), the extension at fracture decreased continuously as the time to frac-

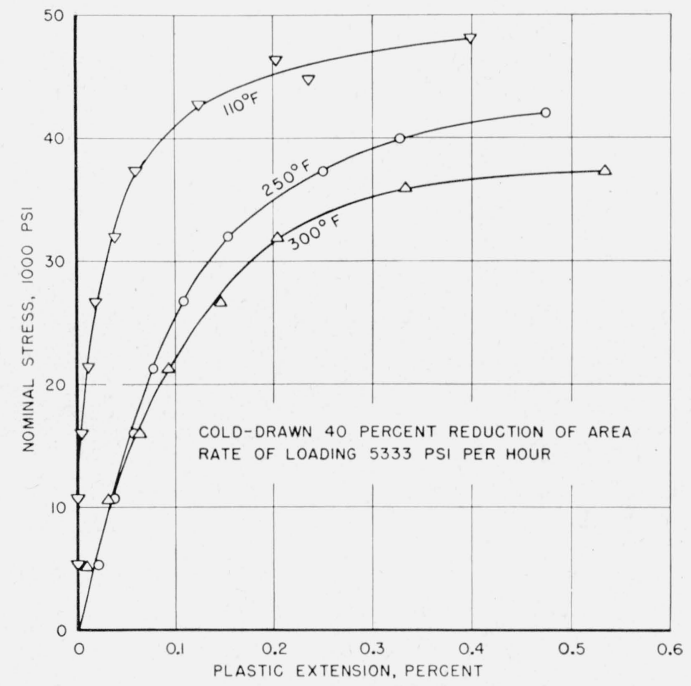

Figure 1. Effect of nominal stress on plastic extension of cold-drawn copper at different temperatures.

The values for extension are those obtained after the application of the loads for a period of 1 houi

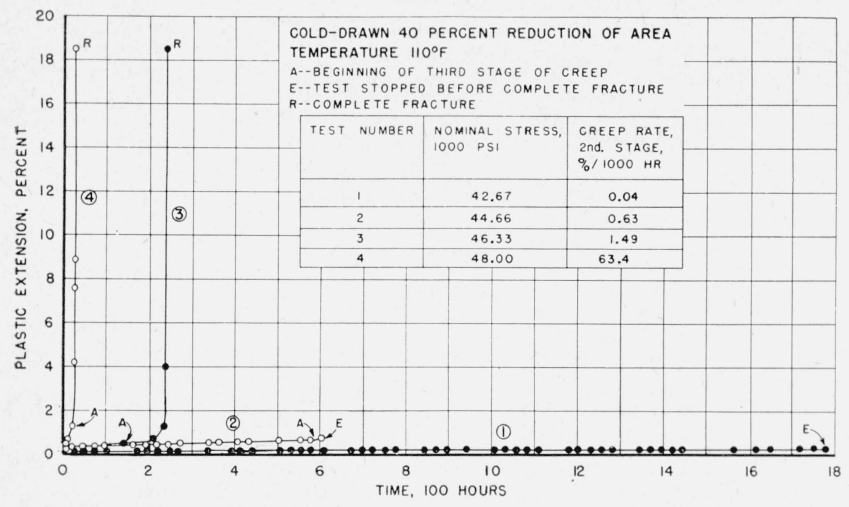

Ftgure 2. Extension-time curves for cold-drawn copper specimens tested in creep at $110^{\circ} \mathrm{F}$. ture increased. At $80^{\circ} \mathrm{F}$ (table 1), the extensions at the maximum load and at fracture were less than the extensions at the beginning of the third stage and at fracture, respectively, of many of the specimens tested under creep conditions; at $80^{\circ} \mathrm{F}$, the time to fracture was only about $1 \mathrm{hr}$. At constant temperature, reversals also were observed in the extension-time relationship at the beginning of the third stage (table 2), but the time to the beginning of the third stage and to fracture increased continuously with decrease in creep stress. At constant creep rate (average in second stage), the time to attain the third stage and the extent of this stage both increased with increase in test temperature. These features should be considered in the commercial application under conditions of creep of colddrawn copper and the interpretation of stress-rupture data.

With annealed copper, the characteristics of the extension-time curves were similar to those previously described [1]. In the present tests (fig. 5), the extensions at the beginning of the second stage, third stage, and at fracture usually decreased with increase in the duration of the creep test at each temperature investigated. An important feature, however, was shown in the creep behavior after the beginning of the third stage of a specimen tested at $110^{\circ} \mathrm{F}$ and with a relatively slow rate $(2.75 \% / 1,000$

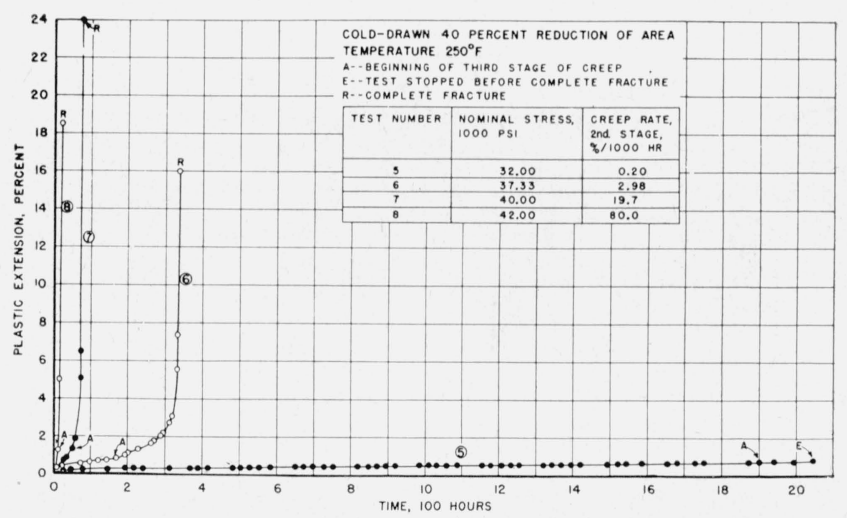

FiguRE 3. Extension-time curves for cold-drawn copper specimens tested in creep at $250^{\circ} \mathrm{F}$.

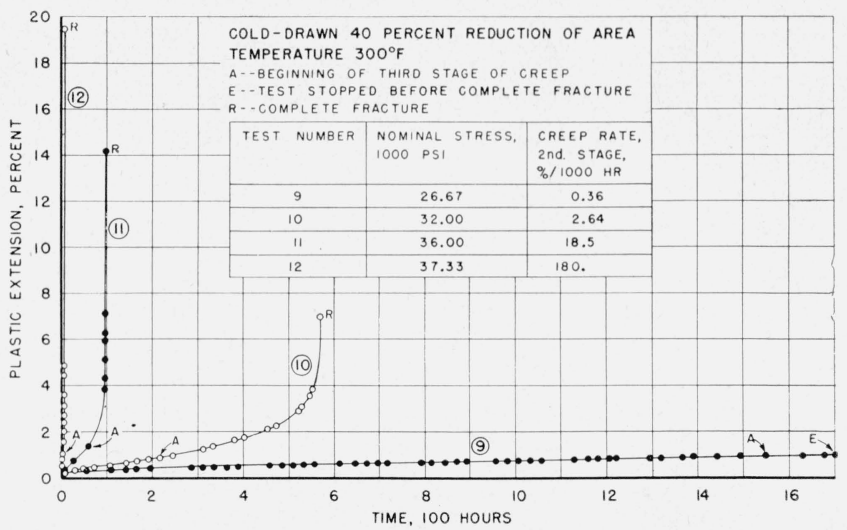

Figure 4. Extension-time curves for cold-drawn copper specimens tested in creep at $300^{\circ} \mathrm{F}$. 


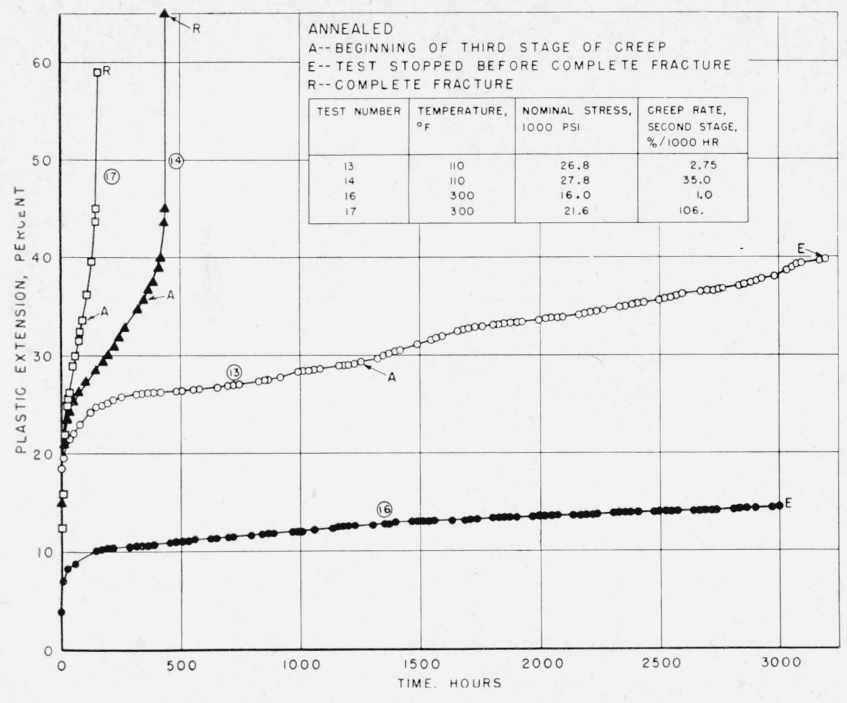

Figure 5. Extension-time curves for annealed copper specimens tested in creep at $110^{\circ}$ and $300^{\circ} \mathrm{F}$.

hr, test 13). After the beginning of the third stage (point $\mathrm{A}$ ), the creep rate materially increased and continued in excess of the average rate in the second stage for a period of about $500 \mathrm{hr}$. At the end of this period the specimen attained an average creep rate of 3.8 percent per $1,000 \mathrm{hr}$ for a period of about $1,000 \mathrm{hr}$ before again increasing rapidly.

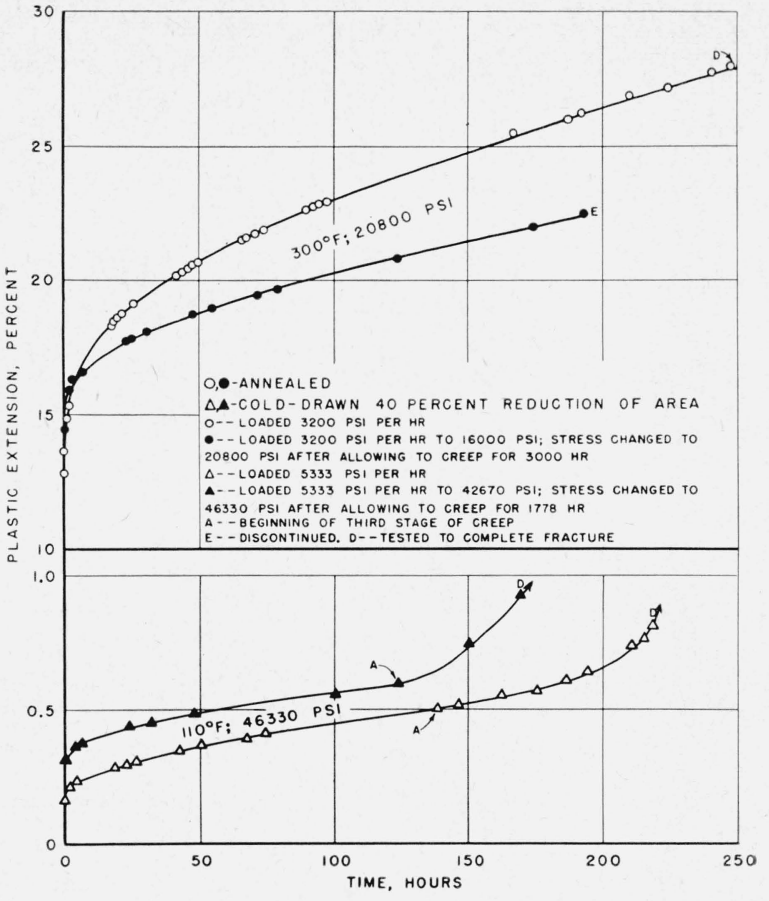

FIGURE 6. Effect of rate of loading on creep of annealed copper at $300^{\circ} \mathrm{F}$ and of cold-drawn copper at $110^{\circ} \mathrm{F}$.

TABLE 2. Results of creep tests on high-purity copper initially as bright annealed and as cold-drawn 40-percent reduction of area

\begin{tabular}{|c|c|c|c|c|c|c|c|c|c|c|c|}
\hline \multirow{2}{*}{ Number } & \multirow{2}{*}{$\begin{array}{l}\text { Test tem- } \\
\text { perature }\end{array}$} & \multirow{2}{*}{$\begin{array}{l}\text { Nominal } \\
\text { creep } \\
\text { stress }\end{array}$} & \multirow{2}{*}{$\begin{array}{l}\text { Average } \\
\text { creep } \\
\text { rate, } \\
\text { second } \\
\text { stage }\end{array}$} & \multicolumn{3}{|c|}{ Beginning of third stage } & \multicolumn{4}{|c|}{ End of test } & \multirow{2}{*}{ Remarks } \\
\hline & & & & Time & $\begin{array}{c}\text { Plastic } \\
\text { extension }\end{array}$ & $\begin{array}{l}\text { True } \\
\text { stress }\end{array}$ & Time & $\begin{array}{c}\text { Plastic } \\
\text { extension }\end{array}$ & $\begin{array}{l}\text { Reduc- } \\
\text { tion of } \\
\text { area }\end{array}$ & $\begin{array}{l}\text { True } \\
\text { stress }\end{array}$ & \\
\hline \multicolumn{12}{|c|}{ A. Annealed; rate of loading, $3,200 \mathrm{psi} / \mathrm{hr}$} \\
\hline $\begin{array}{c}18 \\
13 \\
14 \\
19 \\
21 \\
15 \\
22 \\
23 \\
16 \\
\\
\text { a } 16 \mathrm{~A} \\
24 \\
20 \\
17\end{array}$ & $\begin{array}{l}{ }^{\circ} F \\
110 \\
110 \\
110 \\
110 \\
250 \\
250 \\
250 \\
250 \\
300 \\
300 \\
300 \\
300 \\
300\end{array}$ & $\begin{array}{c}1,000 \text { psi } \\
25.6 \\
26.8 \\
27.8 \\
28.8 \\
16 \\
19.2 \\
22.4 \\
24 \\
16 \\
\\
20.8 \\
19.2 \\
20.8 \\
21.6\end{array}$ & $\begin{array}{c}\% / 1,000 \mathrm{hr} \\
1.08 \\
2.75 \\
35 \\
165 \\
0.33 \\
1.04 \\
10.1 \\
130 \\
1 \\
24.5 \\
8.3 \\
36.4 \\
106\end{array}$ & \begin{tabular}{r}
\multicolumn{1}{c}{$h r$} \\
\hdashline 1,250 \\
340 \\
105 \\
\hdashline 1,248 \\
134 \\
---
\end{tabular} & $\begin{array}{c}\% \text { in } 2 \text { in. } \\
-39.2 \\
35.7 \\
42.2 \\
--.- \\
-35.7 \\
41.2 \\
-.--\end{array}$ & $\begin{array}{c}1,000 \mathrm{psi} \\
-34.6 \\
37.7 \\
40.9 \\
---- \\
-30 \\
33.9 \\
--\cdot-\end{array}$ & 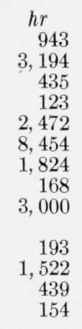 & $\begin{array}{c}\text { \% in } 2 \text { in. } \\
19 \\
39.7 \\
65 \\
62.5 \\
8.94 \\
23.14 \\
48.9 \\
59.4 \\
14.43 \\
\\
22.5 \\
36.5 \\
46 \\
59\end{array}$ & $\begin{array}{l}\% \\
16 \\
28.1 \\
90 \\
89.7 \\
8.19 \\
18.8 \\
34.3 \\
78.7 \\
12.6 \\
16.7 \\
33 \\
46.7 \\
61.1\end{array}$ & $\begin{array}{c}\text { 1,000 psi } \\
30.5 \\
37.3 \\
289 \\
278.6 \\
17.4 \\
23.6 \\
34.1 \\
112.4 \\
18.3 \\
\\
21.4 \\
28.8 \\
39 \\
55.5\end{array}$ & $\begin{array}{l}\text { Test stopped in second stage. } \\
\text { Test stopped in third stage. } \\
\text { Tested to complete fracture. } \\
\text { Do. } \\
\text { Test stopped in second stage. } \\
\text { Do. } \\
\text { Test stopped in third stage. } \\
\text { Tested to complete fracture. } \\
\text { Tested into second stage. Stress changed } \\
\text { to } 20,800 \text { psi and test continued as } 16 \mathrm{~A} \text {. } \\
\text { Test stopped in second stage. } \\
\text { Tested to complete fracture. } \\
\text { Do. } \\
\text { Do. }\end{array}$ \\
\hline \multicolumn{12}{|c|}{ B. Cold-drawn, 40-percent reduction of area; rate of loading, 5,333 psi $/ \mathrm{hr}$} \\
\hline $\begin{array}{c}1 \\
\text { b } 1 \mathrm{~A} \\
2 \\
3 \\
4 \\
5 \\
6 \\
7 \\
8 \\
9 \\
10 \\
11 \\
12\end{array}$ & $\begin{array}{l}110 \\
110 \\
110 \\
110 \\
110 \\
250 \\
250 \\
250 \\
250 \\
300 \\
300 \\
300 \\
300\end{array}$ & \begin{tabular}{l|}
42.67 \\
46.33 \\
44.66 \\
46.33 \\
48 \\
32 \\
37.33 \\
40 \\
42 \\
26.67 \\
32 \\
36 \\
37.33
\end{tabular} & $\begin{array}{c}0.04 \\
1.6 \\
0.63 \\
1.49 \\
63.4 \\
0.20 \\
2.98 \\
19.7 \\
80 \\
0.36 \\
2.64 \\
18.5 \\
180\end{array}$ & $\begin{array}{r}125 \\
587 \\
140 \\
20 \\
1,900 \\
160 \\
50 \\
13 \\
1,550 \\
220 \\
60 \\
4\end{array}$ & $\begin{array}{l}0.6 \\
.69 \\
.50 \\
1.3 \\
0.72 \\
.85 \\
1.3 \\
1.38 \\
0.94 \\
.85 \\
1.4 \\
1.03\end{array}$ & $\begin{array}{l}-\cdots \\
46.9 \\
45 \\
46.6 \\
48.6 \\
32.3 \\
37.8 \\
40.6 \\
42.6 \\
26.9 \\
32.3 \\
36.5 \\
37.7\end{array}$ & $\begin{array}{r}1,778 \\
194 \\
600 \\
236 \\
28 \\
2,041 \\
335 \\
74 \\
18 \\
1,701 \\
569 \\
98 \\
7\end{array}$ & $\begin{array}{l}0.25 \\
20 \\
0.73 \\
18.5 \\
18.5 \\
0.73 \\
16 \\
24 \\
18.5 \\
0.98 \\
7 \\
14.2 \\
19.5\end{array}$ & $\begin{array}{c}0.25 \\
83.6 \\
0.7 \\
84.2 \\
83.2 \\
0.89 \\
52.3 \\
67.2 \\
78.1 \\
0.79 \\
12.3 \\
41.5 \\
78.3\end{array}$ & $\begin{array}{r}42.8 \\
282.5 \\
45.1 \\
293.6 \\
285.6 \\
33 \\
78.2 \\
122 \\
193.9 \\
26.9 \\
36.5 \\
61.5 \\
172.2\end{array}$ & $\begin{array}{l}\text { Tested into second stage. Stress changed } \\
\text { to } 46,330 \text { psi and test continued as } 1 \mathrm{~A} . \\
\text { Tested to complete fracture. } \\
\text { Tested stopped in third stage. } \\
\text { Tested to complete fracture. } \\
\text { Do. } \\
\text { Test stopped in second stage. } \\
\text { Tested to complete fracture. } \\
\text { Do. } \\
\text { Do. } \\
\text { Test stopped in second stage. } \\
\text { Tested to complete fracture. } \\
\text { Do. } \\
\text { Do. }\end{array}$ \\
\hline
\end{tabular}

a For prior thermal-mechanical history, see test 16. Final stress of 4,800 psi applied instantaneously. Temperature unchanged throughout the test. b For prior thermal-mechanical history, see test 1. Final stress of 3,660 psi applied instantaneously. Temperature unchanged throughout the test. 
Creep curves of this type have been observed by Burghoff and Mathewson [3] with single crystals of brass, and Cottrell and Aytekin [4] with single crystals of zinc. The shape of the curve appears to indicate a localized softening effect followed by a strain hardening process that prevents further extension in that region. However, the remaining regions in which the hardening process has been not so effective continue to extend at a rate suggestive of the normal strain hardening-recovery process, which is known to exist during the third stage.

Although the resistance to creep and to fracture was significantly increased by cold-drawing, the copper (as compared to the annealed condition), the superiority in these properties as exhibited in the cold-drawn condition was attended by a marked decrease in plastic extension at each temperature used in the creep tests.

The effects of rate of loading on creep behavior of ingot iron and on annealed copper have been previously described [2, 1]. Additional data obtained on both annealed and cold-drawn copper are presented in figure 6 and table 2 . The extension-time curves for the annealed specimens (fig. 6) indicate that, after an initial adjustment period (first stage) and at equal values of time, the creep rate at $300^{\circ} \mathrm{F}$ was greater for the specimen loaded in the usual manner than for the specimen allowed to creep for $3,000 \mathrm{hr}$ before the application of the same stress $(20,800 \mathrm{psi})$. The extension-time curves obtained at $110^{\circ} \mathrm{F}$ on colddrawn specimens indicate that the creep rate, for equal values of time, extensions at the beginning of third stage and at fracture were greater for the specimens loaded slowly than for the specimens loaded relatively fast to a stress of $46,330 \mathrm{psi}$; the time for initiation of third stage and to fracture was greater for the specimen loaded relatively rapidly.

While the observations made on the annealed specimens appear inconsistent with some of the previous results, they also serve to emphasize the importance of the rate of loading, together with temperature and strain rate on the mechanism of deformation of high-purity copper.

\subsection{Influence of Stress and Temperature on the Average Creep Rate in the Second Stage}

The relation between nominal ${ }^{3}$ stress and creep rate (average in the second stage) at $110^{\circ}, 250^{\circ}$, and $300^{\circ} \mathrm{F}$ for both annealed and cold-drawn copper is shown by the curves of figure 7 . The smooth curves connecting the experimental values as plotted on a semilog basis (fig. 7) or on a log-log basis (not shown) are nonlinear. The sigmoidal curves obtained for some of the test conditions $\left(110^{\circ} \mathrm{F}\right)$ indicate the existence of threshold stresses below which the resulting creep rates are nil. At relatively high stresses, the rate of creep at each temperature increased markedly with a further increase in stress.

Obviously the resistance to creep was materially increased by cold-drawing the copper 40-percent

3 The nominal stress is defined as the stress obtained by dividing the current load by the original area of the specimen.

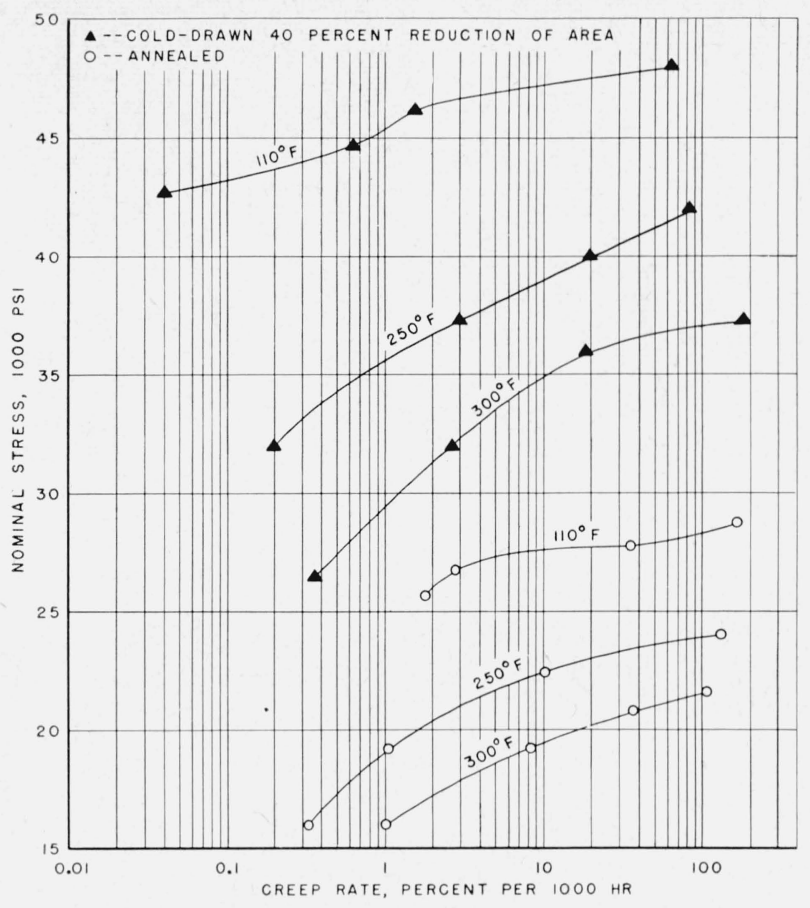

FiguRE 7. Relation between nominal stress and creep rate at different temperatures.

reduction in area (fig. 7). This superiority of the copper in the initially cold-drawn condition increased as the test temperature was decreased. Thus, prestraining at a fast rate at room temperature (colddrawing') improves the creep strength of high-purity copper, and this or other cold-working processes might be very useful in certain commercial applications.

The greater resistance to creep of the cold-drawn copper is still manifested even where comparison of the creep rates of the two initial conditions is made on the basis of equivalent ${ }^{4}$ stress values (fig. 8). If the second-stage creep rates of the copper were independent of the prior strain history, similar or identical curves should be obtained at each test temperature for both the annealed and cold-drawn specimens. At each temperature, the strength of the cold-drawn copper is superior to that of the annealed.

Comparison of the performance of the copper also can be conveniently made on the basis of the true stress ${ }^{5}$ at the beginning of the third stage (table 2). Again, at each temperature, the stresses required to produce equivalent creep rates were greater for the cold-drawn than for the annealed condition. As will be shown later, however, the increase in creep resistance brought about by cold-drawing the copper was attended by an appreciable decrease in creep extension at the operating temperatures.

4 Equivalent stress is defined as the stress obtained by dividing the current load by the original area in the annealed condition (before cold-drawing).

5 The true stress is defined as the stress obtained by dividing the current load by the current area of the specimen. 


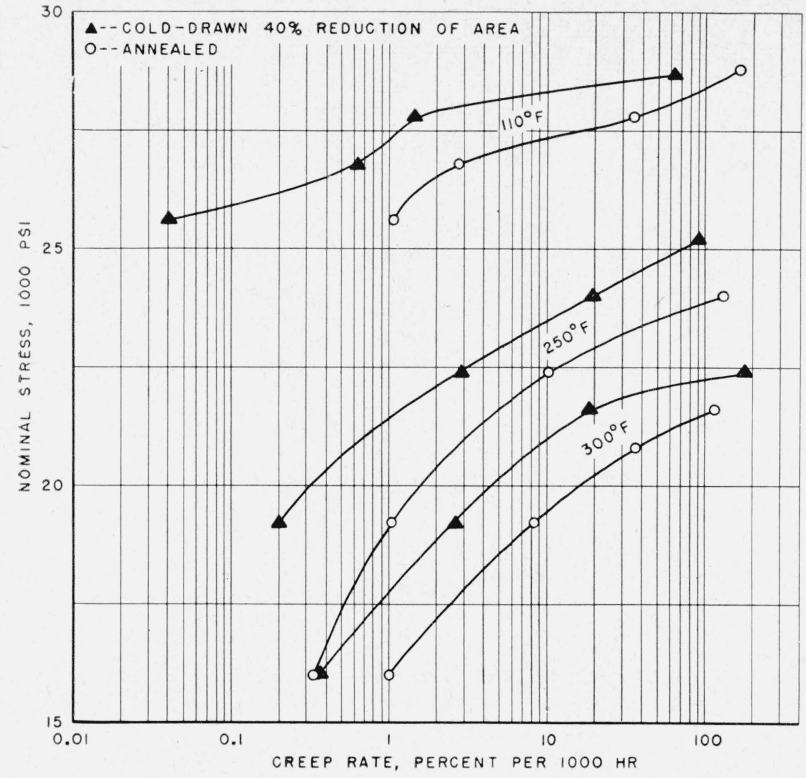

Figure 8. Relation between equivalent nominal stress and creep rate at different temperatures.

\subsection{Variation in Creep Rate With Plastic Extension and Time}

A number of theories have been advanced to explain the relationship between extension and time during the first stage of creep. Among the proposals that have received considerable attention are those of Andrade [5] and Mott and Nabarro [6]. Andrade's analysis postulates that in the transient portion of the creep curve (first stage) the strain varies linearly with the one-third power of the time. Application of this concept would require that all curves for metals and alloys in the transient region should have a slope of minus two-thirds when the logarithm of the creep rate is plotted against the logarithm of time. Accordingly, the slope should be independent of test temperature and applied stress. Mott and Nabarro, however, developed a theory for exhaustion creep in which the strain was found to be proportional to a value dependent on the applied shear stress, absolute temperature to the two-thirds power, and the logarithm of the time to the two-thirds power.

The relation between creep rate and time during the first stage of creep of the annealed and colddrawn copper is shown in figure 9. The present results are consistent with those previously shown $[1,2,7]$. For any constant temperature used, the creep rate-time cycles are more evident at the lower than at higher stresses, and the slopes of the curves (as drawn through average values) tend to increase as the stress is increased. Obviously, the slopes of these curves are approximately equal only when the mechanisms of deformation for the specimens under consideration are approximately equivalent.

It has been suggested [1] that deformation during creep occurs by a discontinuous process. The rela-

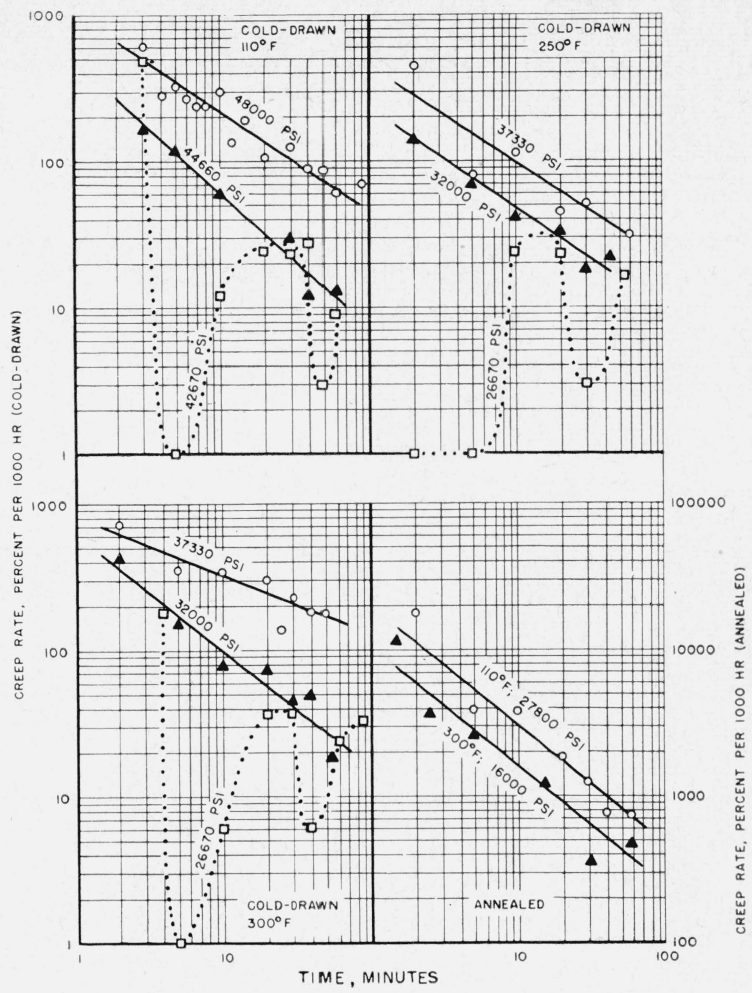

FiguRE 9. Variation in creep rate in the first stage with time at different temperatures and with different nominal stresses.

tionship between creep rate and plastic extension occurring during creep of the cold-drawn copper is shown in figures 10,11 , and 12 . The magnitude of the creep rate-extension cycles is greater during the second stage than in either the first or third stage. At constant temperature, moreover, the magnitude and frequency of occurrence of these cycles are decreased as the stress is raised. The rate of loading also affects the occurrence of these cycles, as is illustrated by the two curves in figure 10 for specimens tested at a stress of 46,330 psi. These results confirm qualitatively those previously presented for ingot iron, annealed copper, and cold-drawn aluminum, and lends further credence to the belief that during second-stage creep there is a delay in the balance between strain hardening and recovery.

\subsection{Effect of Creep Rate on Ductility}

Previous results [1] of creep tests made with annealed copper indicated that, in general, the extension at the beginning of the third stage increased with increase in creep rate (constant temperature) and with a decrease in temperature (constant creep rate). However, it was pointed out that the increase in values for extension at the beginning of the third stage approached a limit beyond which the extension would not increase with an increase in creep rate or a decrease in test temperature.

The relation between creep rate (average, second stage) and plastic extension at the beginning of the 


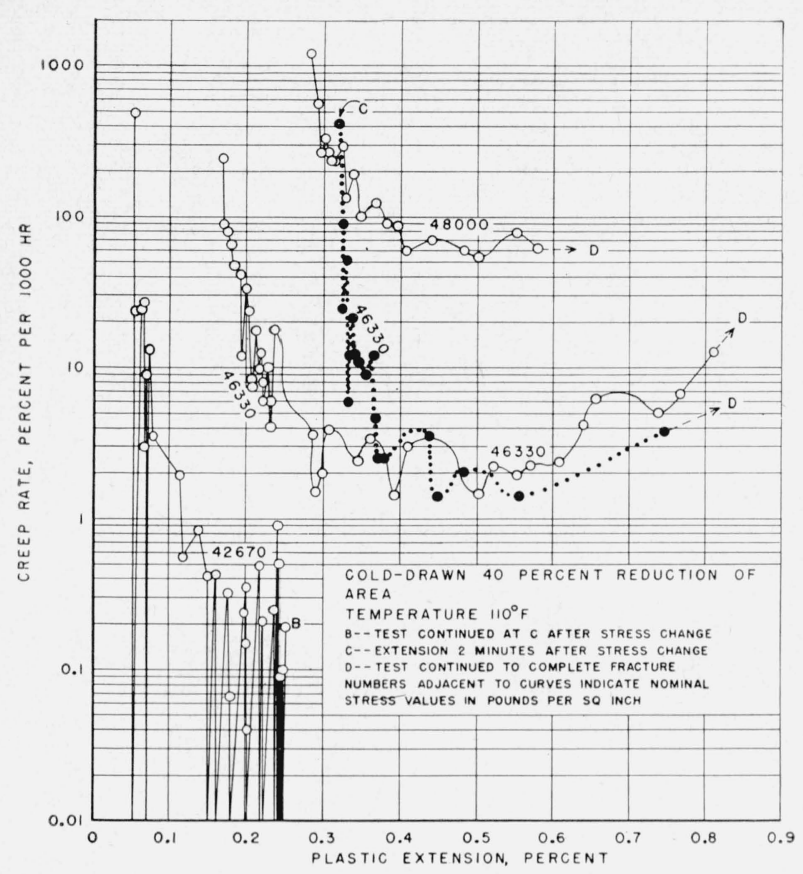

Figure 10. Variation in creep rate of cold-drawn copper with plastic extension at $110^{\circ} F$ and with different nominal stresses.

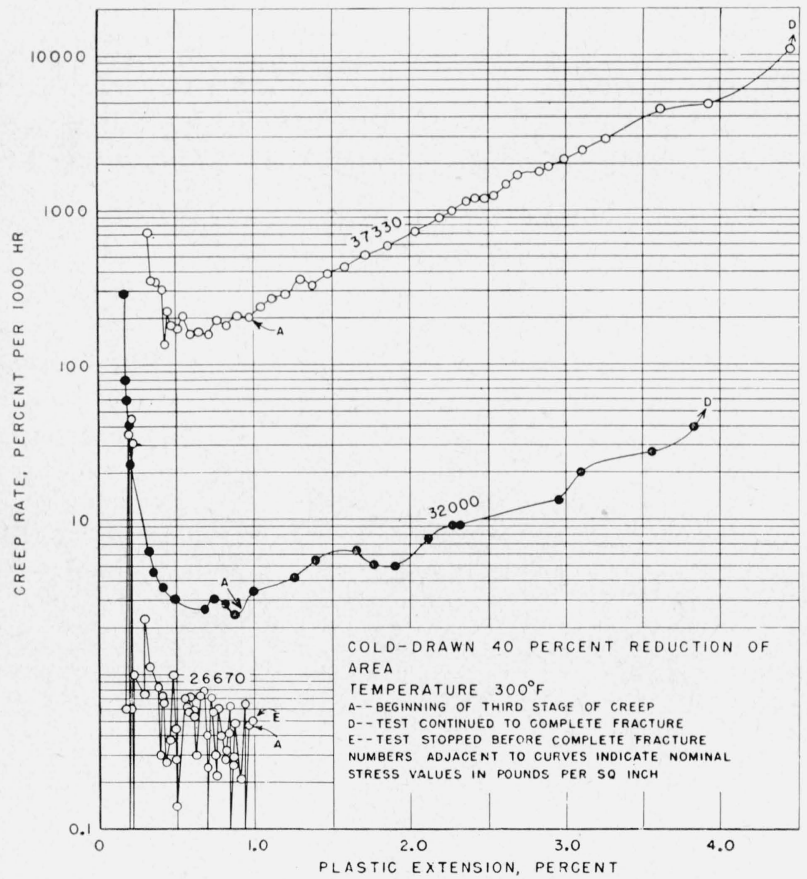

Figure 11. Variation in creep rate of cold-drawn copper with plastic extension at $300^{\circ} \mathrm{F}$ and with different nominal stresses.

third stage of creep of the cold-drawn copper is shown in figure 13. The general pattern of these curves, similar to those already presented, shows a series of reversals that depend upon the mode of deformation

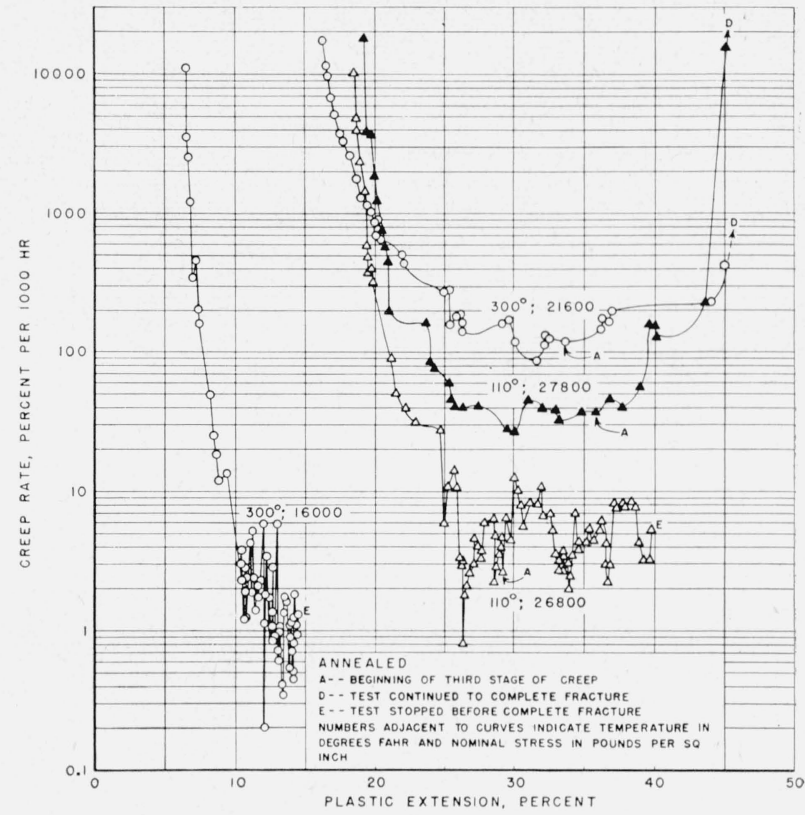

Figure 12. Variation in creep rate of annealed copper with plastic extension at different temperatures and different nominal stresses.

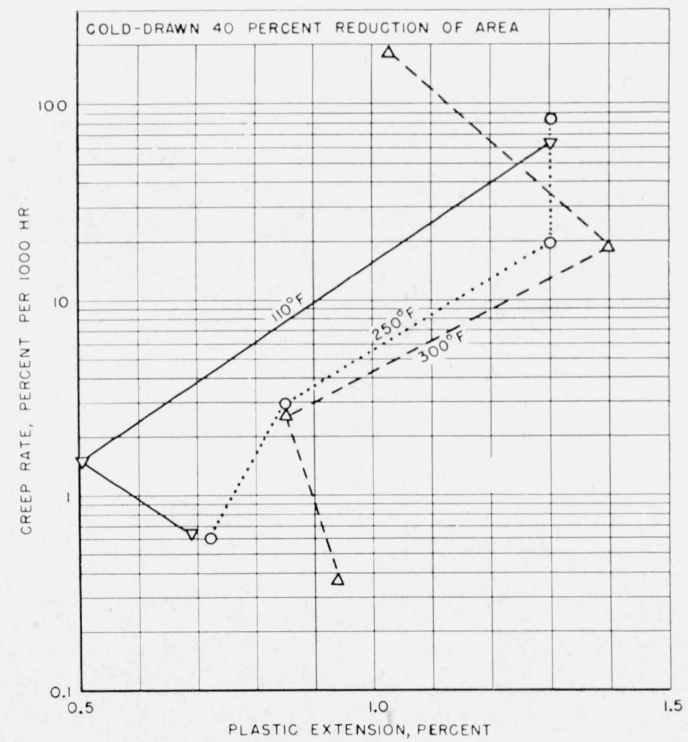

FiguRE 13. Influence of creep rate on plastic extension at the beginning of the third stage of creep of cold-drawn copper at different temperatures.

as affected by variations in both creep rates and in temperatures. That is, the balance between recovery and work-hardening of the initially cold-worked copper varied with the strain rate and test temperature in the creep tests. In some cases, recovery predominated, whereas in other cases work-hardening either predominated or just balanced the effect of recovery.

The effect of creep rate (average in second stage) on plastic extension and reduction of area at fracture 


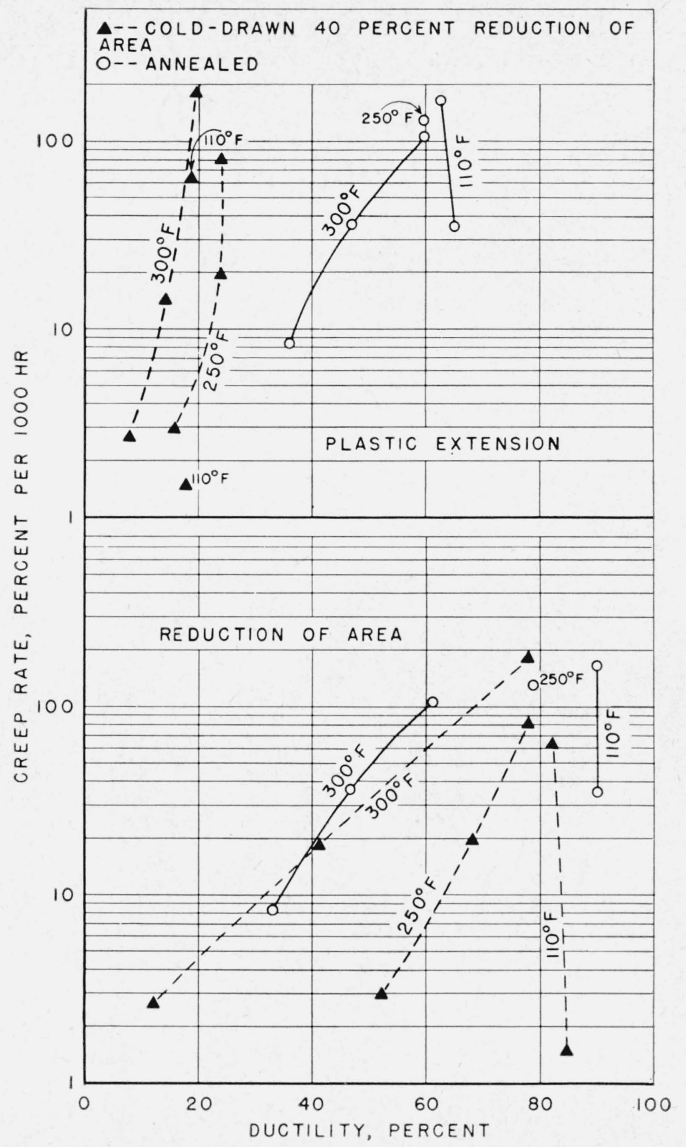

FIgURE 14. Influence of creep rate on ductility at fracture of annealed and cold-drawn copper at different temperatures.

(ductility) of both the annealed and cold-drawn copper is shown in figure 14. Regardless of creep rate or temperature used, the plastic extension at fracture was significantly greater for the annealed than for the cold-drawn copper, but this superiority in ductility in creep of the annealed condition was not always maintained when comparisons were made of the reduction of area values; at equivalent creep rates and a test temperature of either $250^{\circ}$ or $300^{\circ} \mathrm{F}$, the values for reduction of area were nearly alike for both conditions.

For the annealed copper, the values for plastic extension at fracture were of the same order of magnitude for all conditions used, except two tests made at $300^{\circ} \mathrm{F}$. At this temperature, both the extension and reduction of area increased appreciably with an increase in creep rate. At $110^{\circ} \mathrm{F}$, variations in creep rates over the range investigated had no material effect on the reduction of area.

For the cold-drawn copper, the trend was for the ductility at fracture to increase with an increase in creep rate at $250^{\circ}$ and $300^{\circ} \mathrm{F}$; the plastic extension at fracture did not materially change with an increase in creep rate from 20 to 80 percent per 1,000 hr. At $110^{\circ} \mathrm{F}$, variations in creep rate had no appreciable effect on the ductility. At equivalent creep rates, the trend was for the reduction of area to

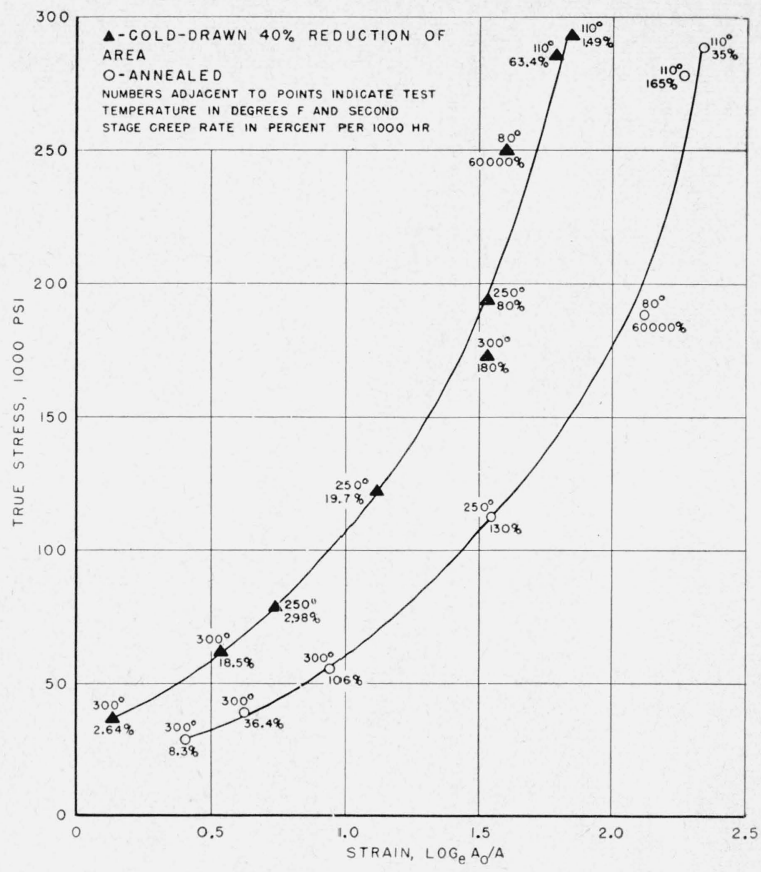

FIGURE 15. Relation between true stress and strain at fracture of annealed and cold-drawn copper specimens tested at different temperatures and creep rates.

increase as the test temperature was decreased, but no consistent relation was shown between the plastic extension at fracture and test temperature.

\subsection{Relation of True Stress to True Strain at Complete Fracture}

The effect of plastic deformation on the fracture stress of specimens tested at different temperatures and creep rates is shown in figure 15. At equal values for true-strain ${ }^{6}$ in creep at fracture, the true-stress values for the cold-drawn copper are higher than those for the annealed copper. The gradual change in slopes of the smooth curves representing the locus of fracture in creep under varying conditions of temperature and strain rate indicate that there is a gradual change in mode of deformation during creep leading to fracture and in the mode of fracture of both the annealed and cold-drawn copper. However, the fact that no single displacement of values will cause the two curves to coincide supports the belief that these characteristics are affected by the prior strain history of the copper.

\subsection{Influence of Strain History on Recovery}

The effect of prior strain history on the stressstrain characteristics of annealed copper during unloading at the same temperature at which the creep test was carried out, was discussed in a previous paper [1]. Data obtained on additional specimens of annealed and of cold-drawn copper are

$\epsilon$ True strain at fracture is the value obtained by taking the natural logarithm of the ratio of the initial cross-sectional area of the specimen prior to testing in creep to the cross-sectional area of the specimen at complete fracture. 
summarized in figure 16 . The change in total extension (elastic and plastic) after completely unloading, was a maximum for the annealed specimen (curve 13) that was tested in creep with a stress of 26,700 psi. at a temperature of $110^{\circ} \mathrm{F}$ to an extension of approximately 40 percent. The slope of the curves for the two cold-drawn specimens (curves 5 and 9) was nearly alike (except for the somewhat greater contraction of specimen 9 upon the removal of the last stress), but their slope was different from those obtained for the annealed specimens (curves 13 and 15). This difference indicates that the recovery behavior of the high-purity copper is affected by its prior strain history.

\subsection{Influence of Strain Rate, Temperature, and Deformation on Hardness at Room Temperature}

The relation of hardness at room temperature and reduction of area to the distance from the fractured end of specimens tested in creep at $110^{\circ}, 250^{\circ}$, and

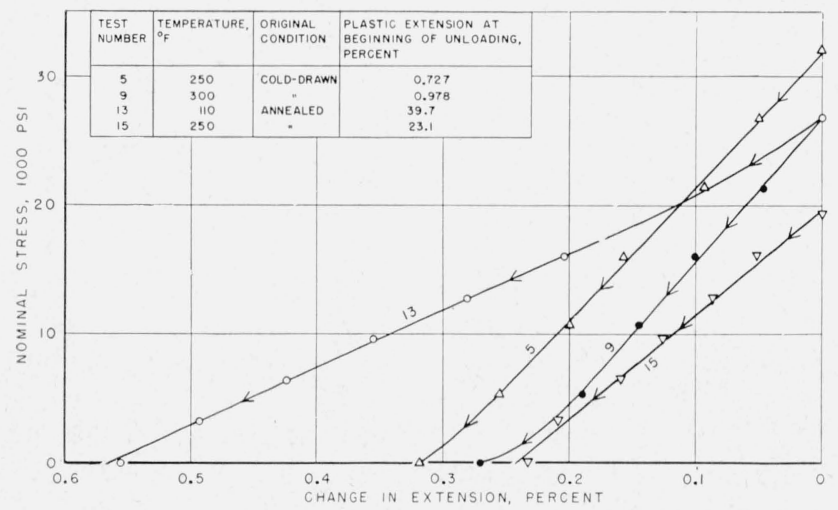

Figure 16. Change in total extension during unloading of specimens of annealed and cold-drawn copper initially at different temperatures and stresses.

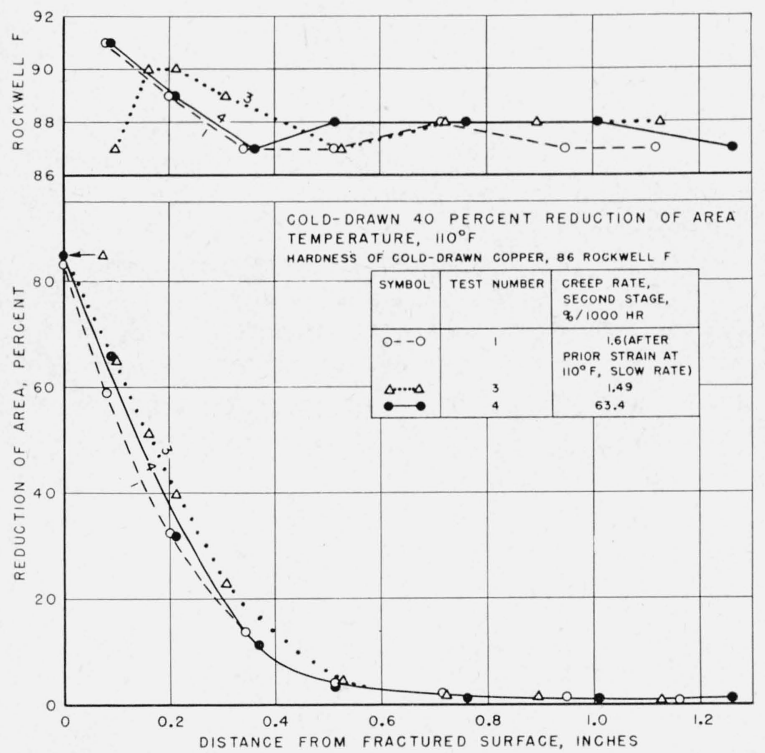

Figure 17. Effect of creep rate and distance from complete fracture on reduction of area and hardness at room temperature of cold-drawn copper fractured at $110^{\circ} \mathrm{F}$. $300^{\circ} \mathrm{F}$ is given in figures $17,18,19$, and 20 . Provided necking occurs, it is to be normally expected that the hardness induced by deforming the copper in creep would attain a maximum in the vicinity of fracture (place of maximum deformation) and to decrease as the distance in the necked region is increased from the fractured surface. The present results, however, similar to those obtained previously [2], show that the hardness-distance from fracture curves and the propensity for the copper specimens to neck varied with the testing conditions (prior strain and mechanical history, strain rate, and temperature). Thus the maximum value for hard-

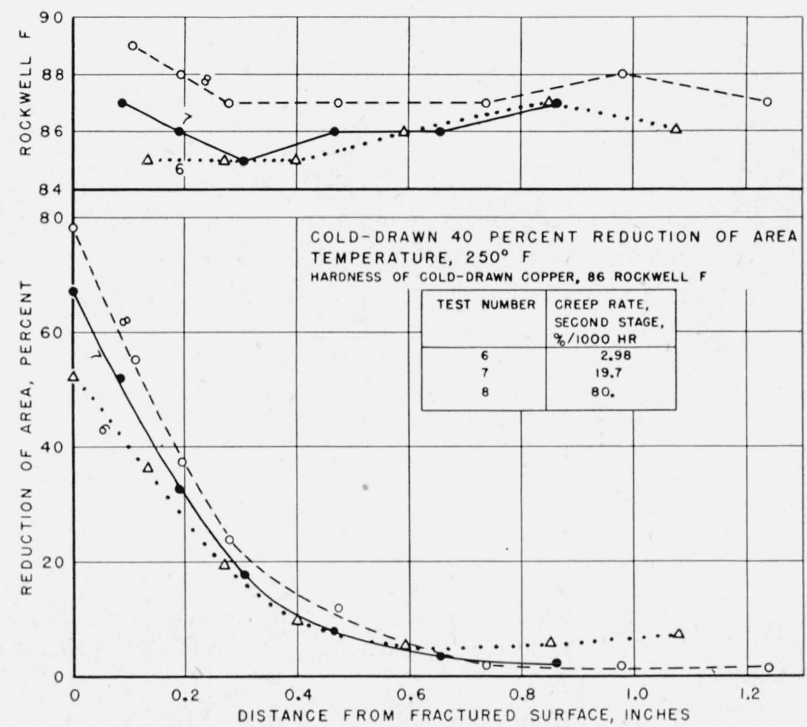

FiguRE 18. Effect of creep rate and distance from complete fracture on reduction of area and hardness at room temperature of cold-drawn copper fractured at $250^{\circ} \mathrm{F}$.

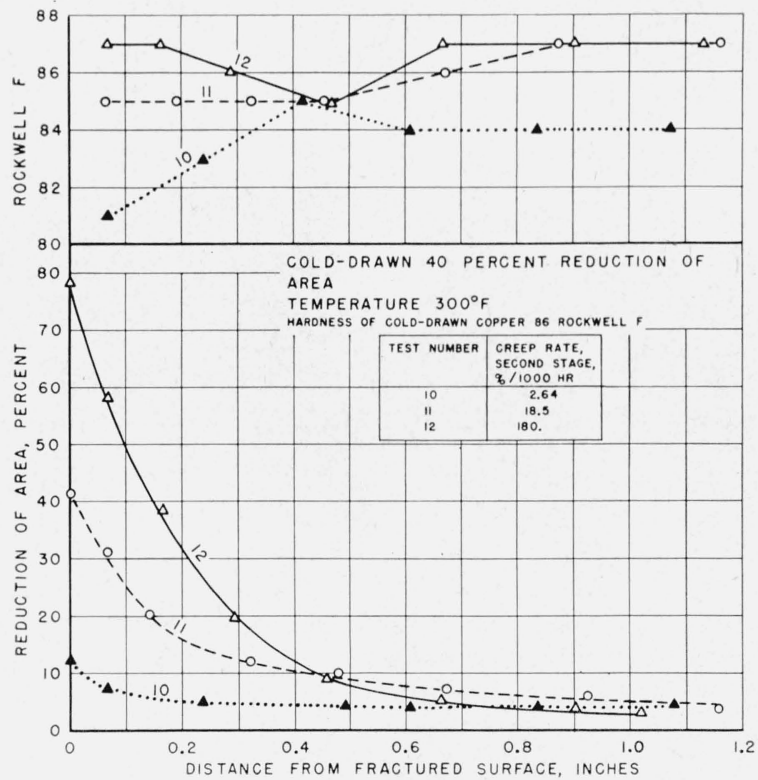

Figure 19. Effect of creep rate and distance from complete fracture on reduction of area and hardness at room temperature of cold-drawn copper fractured at $300^{\circ} \mathrm{F}$. 


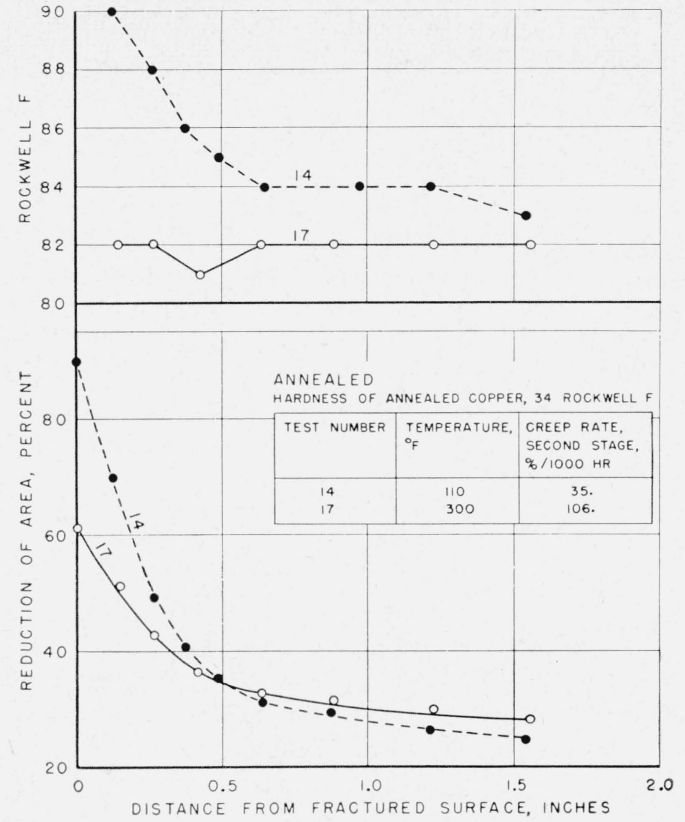

Figure 20. Effect of temperature, creep rate, and distance from complete fracture on reduction of area and hardness at room temperature of annealed copper.

ness obtained in one or more specimens comprising each of the three series of cold-drawn copper (figs. 17, 18 , and 19, respectively) was not at its fractured surface. In general, the degree of necking increased with an increase in creep rate and with a decrease in temperature (fig. 22).

For annealed copper (fig. 20), the hardness at room temperature was a maximum in the vicinity of the fracture of a specimen tested in creep at $110^{\circ} \mathrm{F}$, but no material difference in hardness with distance from the facture end was obtained in a specimen tested at $300^{\circ} \mathrm{F}$. Both of these specimens showed appreciable necking.

The change in hardness at room temperature with deformation (reduction of area) as affected by creep rate and temperature is illustrated in figure 21 . The general trend was for the induced hardness to increase with creep rate and decrease in temperature.

\subsection{Metallography}

The influence of creep rate, temperature, and deformation on the structural and fracture characteristics of the initially cold-drawn copper is illustrated by representative photomicrographs reproduced in figures 23 to 27 . The grains were elongated in the direction of drawing (figs. 23, A, and 26, A), and the elongated grains were further elongated during creep (fig. 23) in the direction of the applied stress; the degree of elongation varied with the test conditions as fast rates and low temperatures both favored this condition.

The fractures were predominantly transcrystalline in all specimens fractured in creep (fig. 23), although some intercrystalline cracking occurred at the deformation corresponding to the beginning of the third

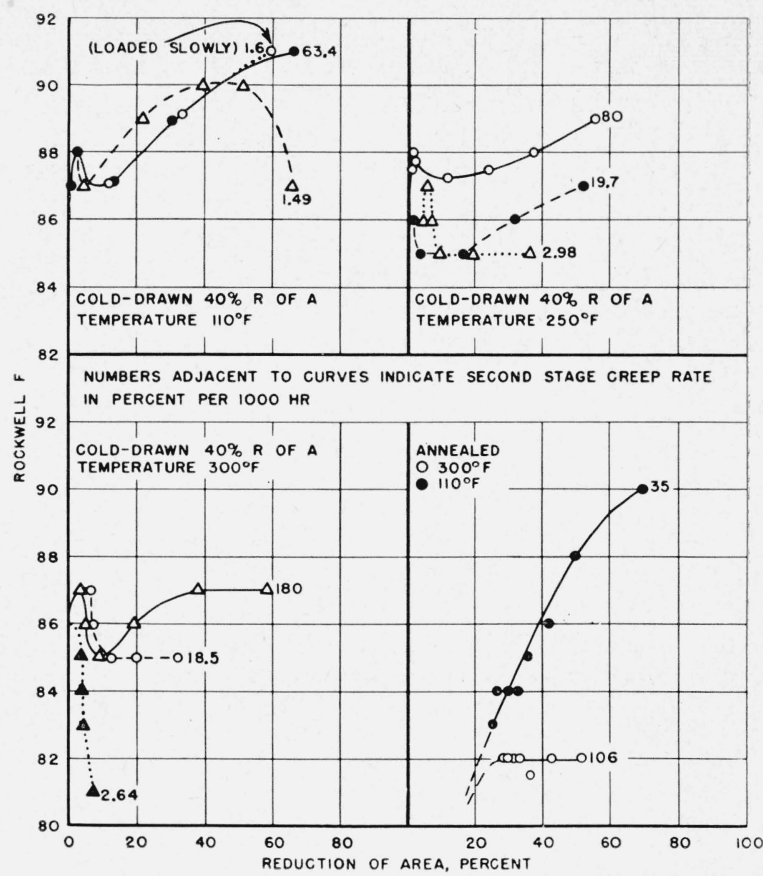

Figure 21. Effect of plastic deformation at different iemperatures and creep rates on hardness at room temperature.

stage in a specimen tested at $300^{\circ} \mathrm{F}$ with a creep rate of $18.5 \% / 1,000 \mathrm{hr}$. (fig. 24, F). A general disintegration is evident even at the beginning of the third stage in this latter specimen, whereas cracks of microscopic dimensions in specimens tested at $110^{\circ}$ or $250^{\circ} \mathrm{F}$ were confined principally to the vicinity of complete fracture. Thus, the beginning of the third stage of creep was attended by cracks of microscopic dimensions (fig. $24, \mathrm{~F}$ ), but the presence of such cracks was not a prerequisite for the initiation of the third stage of creep in the initially cold-drawn copper (fig. 24, E). The evidence thus indicates that under slow creep rates cracks are nucleated at various sites in the vicinity of the axis of the specimen, and as the test continues these cracks grow and subsequently join (fig. 24, D) to form the main path of the complete fracture. In creep tests made at relatively high rates and low temperatures, cracking appears to be initiated solely at or near the axis of the specimen, and these cracks grow and extend outward to the periphery and the final fracture is that of the "rim." As the rim is the final section to fracture, the "flow lines" formed during the progress of the fracture follow the contour of the rim (figs. $24, \mathrm{~B}$, and 25, A). The formation of a "neck" and the accompanying rim is accentuated by fast creep rates and low temperatures (fig. 22). Hence, the abnormal fracture stress often reported for highpurity copper can be attributed partly to this characteristic. When appreciable necking occurs, the fracture is predominantly transcrystalline (fig. 23).

The parent grains of the cold-worked copper (fig. 26 , A) were also broken down during creep to subcrystals whose occurrence, size, and dimensions varied with the test conditions of temperature (fig. 26), 


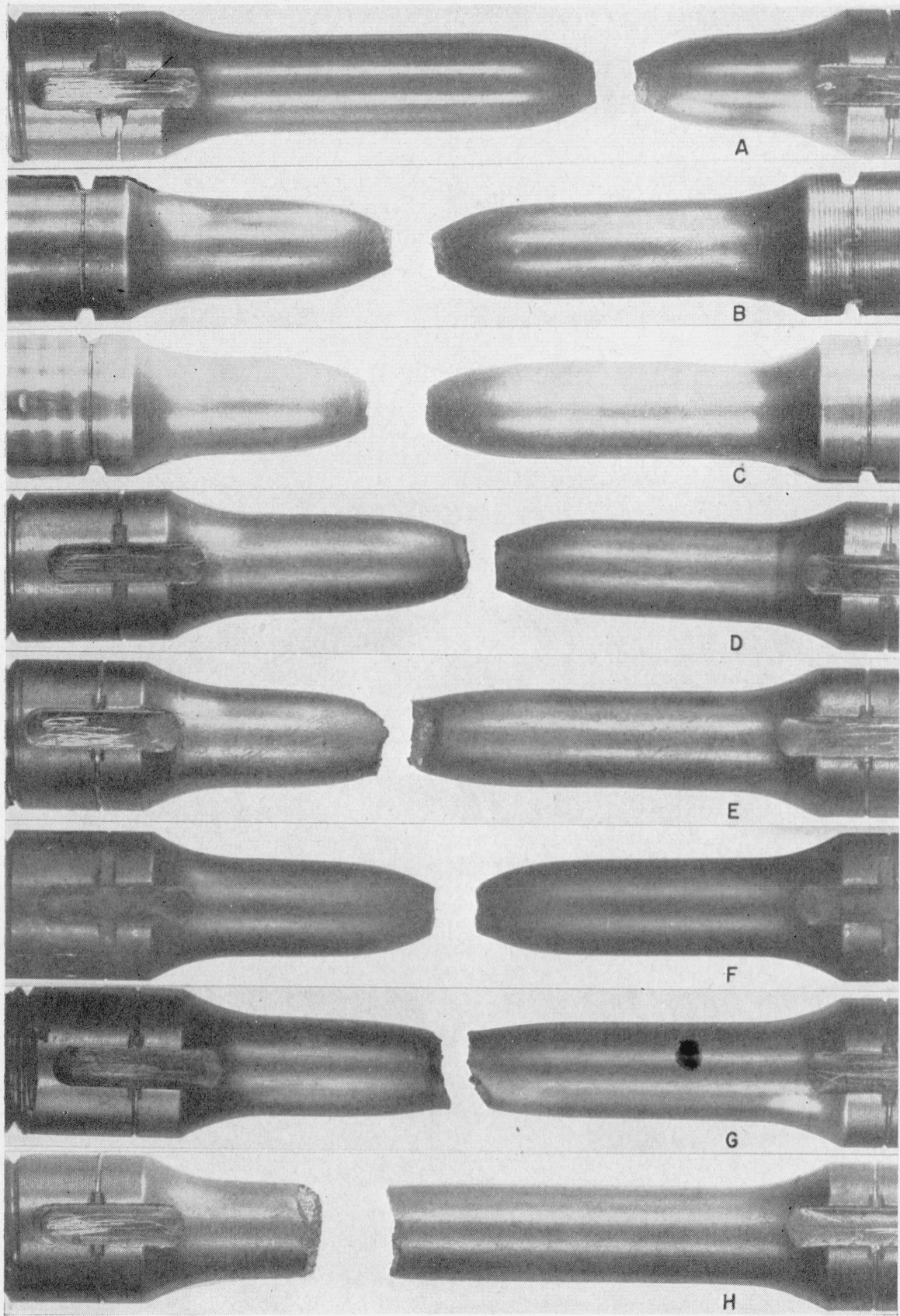

Figure 22. Specimens of colddrawn copper after fracturing at different temperatures and rates; $\times 1$.

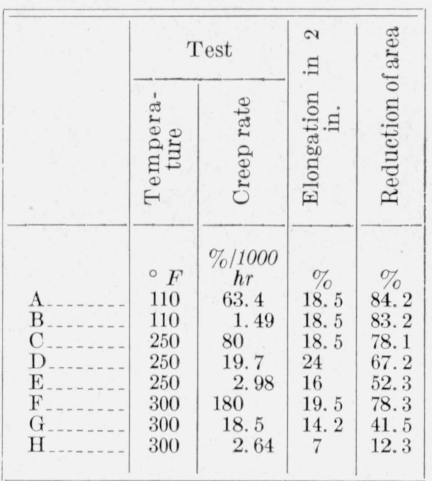

creep rate (fig. $27, \mathrm{~A}$, and $\mathrm{B}$ ) and deformation (fig. $27, \mathrm{C}$, and D). In some cases, only a portion of the parent grain broke down into subcrystals (fig. 27, B), and in other grains no subcrystals were observed (fig. 26, D). The general trend was for the size of these subcrystals to increase with the test temperature and deformation and with decrease in creep rate. For like test conditions, apparently the size of the subcrystals was appreciably smaller for initially colddrawn than for the annealed copper. This condition is believed to be the result of the 40-percent reduction by cold-drawing prior to testing in creep.

\section{Summary}

Creep tests in tension were made at $110^{\circ}, 250^{\circ}$, and $300^{\circ} \mathrm{F}$ on $\mathrm{OFHC}$ copper initially as bright annealed and as cold-drawn 40-percent reduction of area. Microscopic examination and hardness tests at room temperature were made to ascertain some of the damaging effects due to prior creep.

The period of time to initiate the third stage of creep and fracture of cold-drawn copper increased with decrease in stress (constant temperature) or with decrease in temperature (constant rate, average in second stage). 

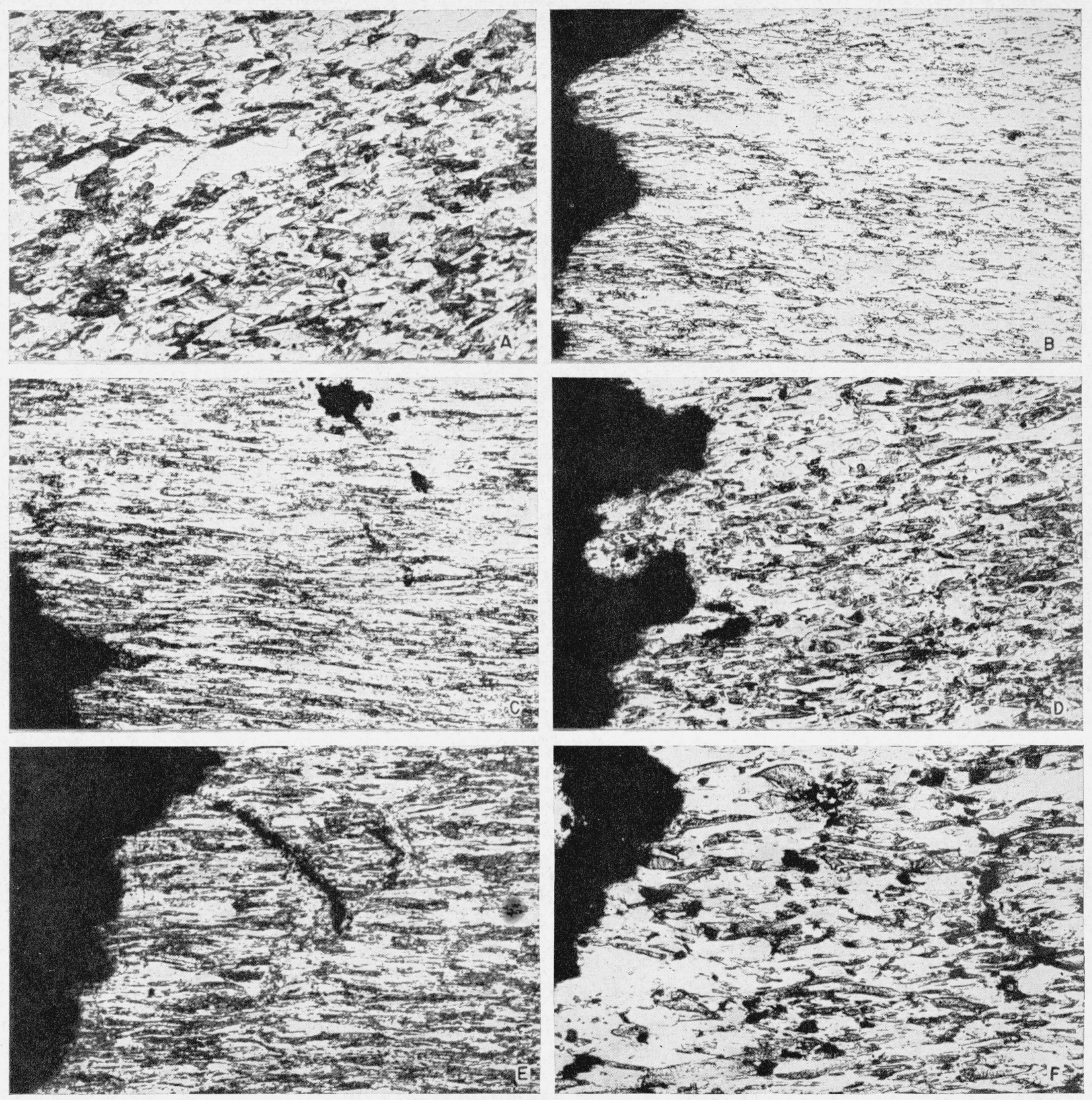

FIGURE 23. Structure of copper initially as cold-drawn 40-percent reduction of area and structures at fracture of specimens tested at different temperatures and rates.

Longitudinal sections etched in equal parts $\mathrm{NH}_{4} \mathrm{OH}$ and $\mathrm{H}_{2} \mathrm{O}_{2}(3 \%)$.

\begin{tabular}{|c|c|c|c|c|c|}
\hline & \multicolumn{2}{|c|}{ Test } & \multirow{2}{*}{$\begin{array}{l}\text { Elongation in } \\
2 \mathrm{in.}\end{array}$} & \multirow{2}{*}{$\begin{array}{l}\text { Reduction of } \\
\text { area }\end{array}$} & \multirow{2}{*}{ Remarks } \\
\hline & Temperature & Creep rate & & & \\
\hline A... & ${ }^{\circ} F$ & $\% / 1000 \mathrm{hr}$ & $\%$ & $\%$ & $\times 75$; as cold- \\
\hline $\begin{array}{l}\mathrm{B} \\
\mathrm{C} \\
\mathrm{D} \\
\mathrm{D} \\
\mathrm{E} \\
\mathrm{F}\end{array}$ & $\begin{array}{l}110 \\
110 \\
250 \\
300 \\
300\end{array}$ & $\begin{array}{c}63.4 \\
1.49 \\
2.98 \\
180 \\
18.5\end{array}$ & $\begin{array}{l}18.5 \\
18.5 \\
16 \\
19.5 \\
14.2\end{array}$ & $\begin{array}{l}83.2 \\
84.2 \\
52.3 \\
78.3 \\
41.5\end{array}$ & $\begin{array}{l}\text { drawn. } \\
\times 100 \\
\times 100 \\
\times 100 \\
\times 100 \\
\times 100\end{array}$ \\
\hline
\end{tabular}




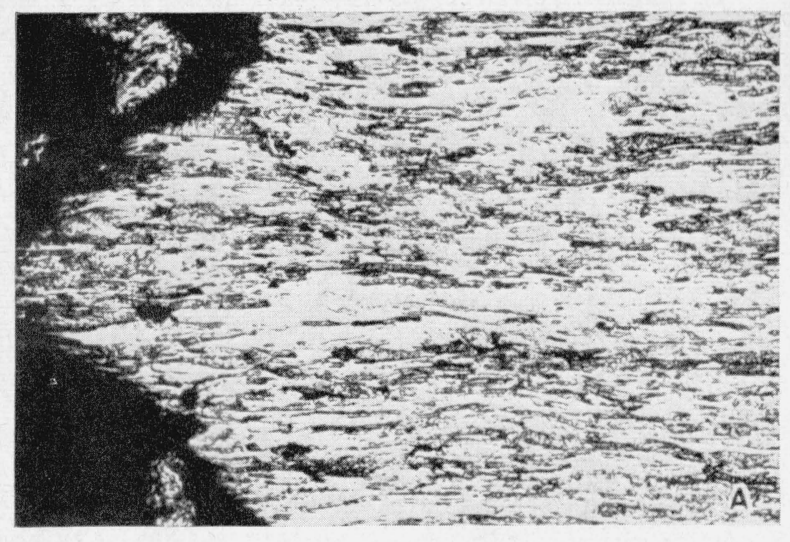

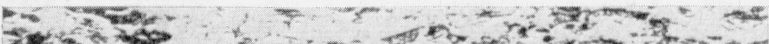

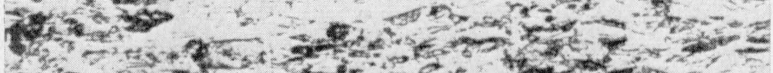

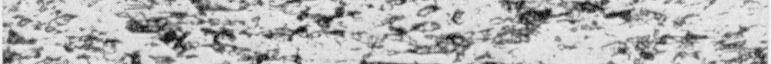

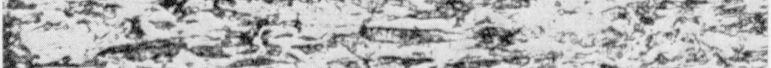

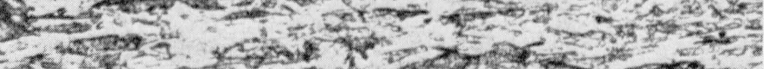

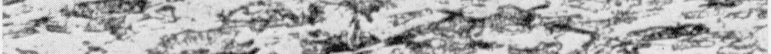

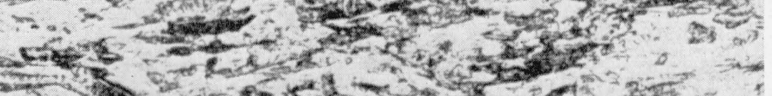

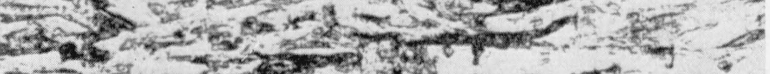

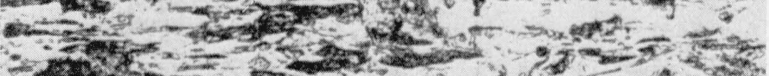

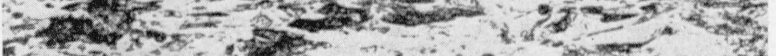

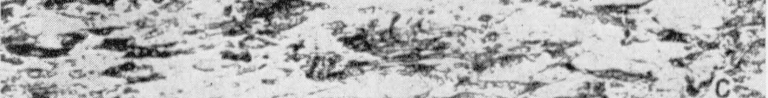

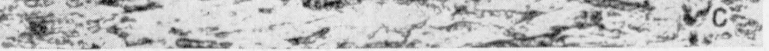

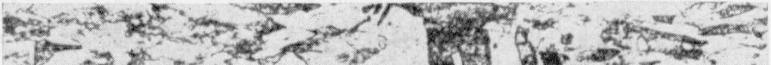

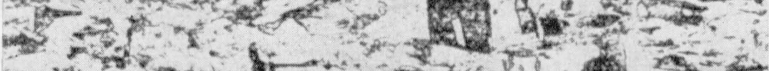

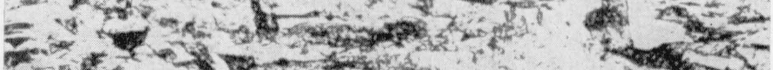

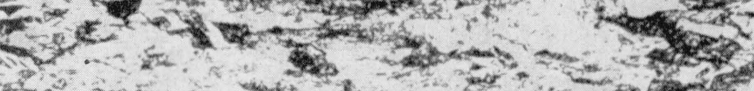

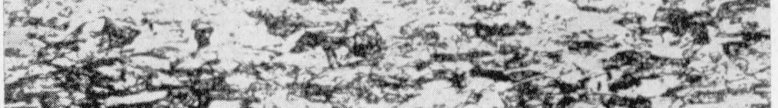

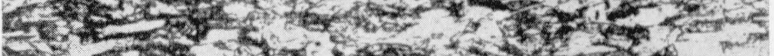

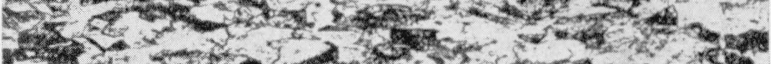

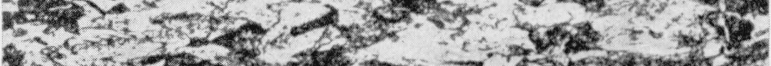

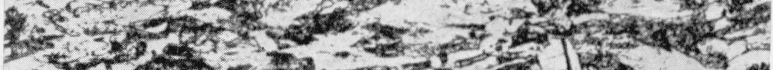

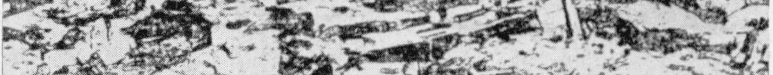

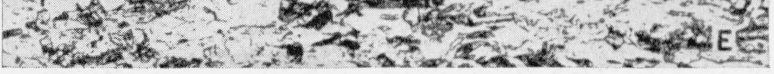

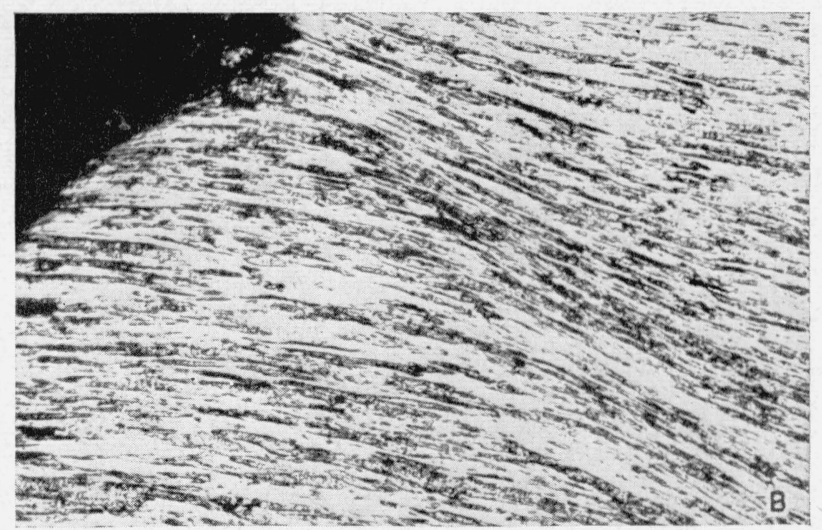

- $\begin{aligned} & 20 \\ & 0\end{aligned}$

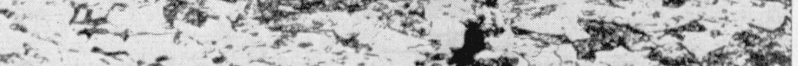

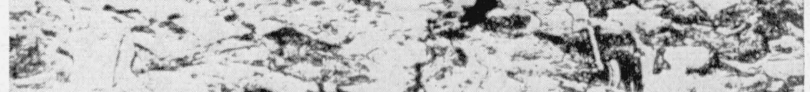

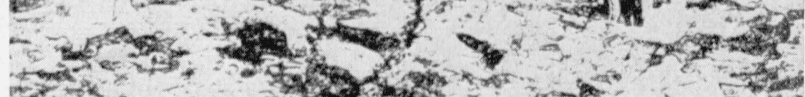

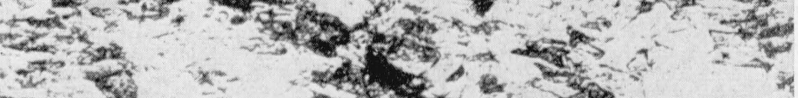

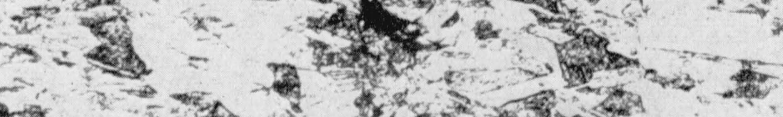

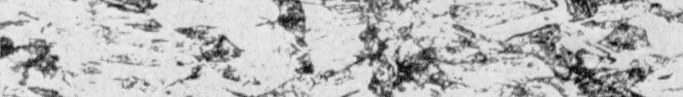
(s)

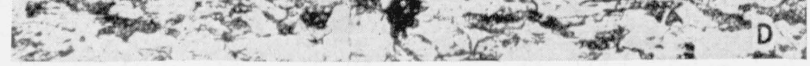

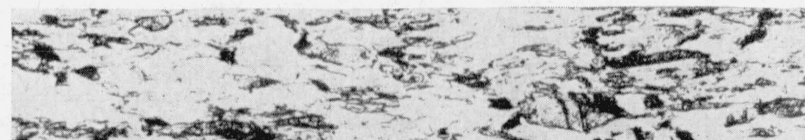

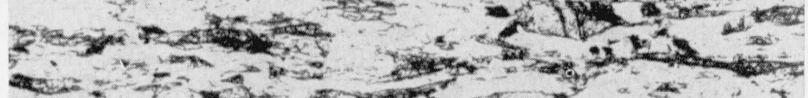

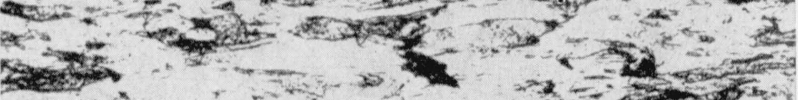
$-x^{2}-x^{2}-y^{2}+20$

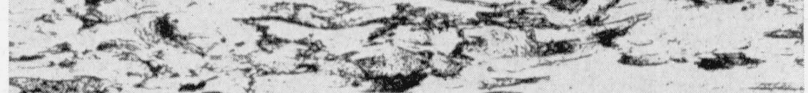

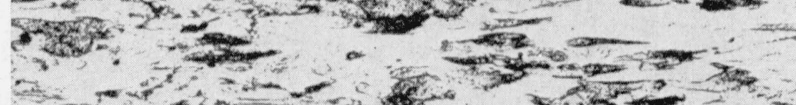

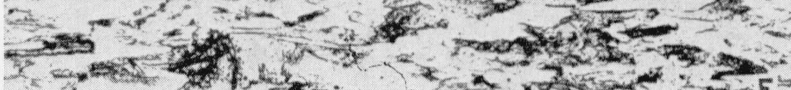

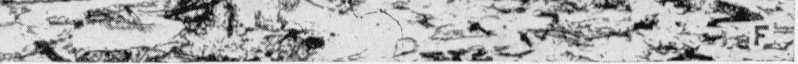

FiguRE 24. Effect of temperature, rate, and plastic deformation on microcracking of copper initially as cold-drawn 40percent reduction of area.

Longitudinal sections near axis of specimen except as indicated, etched in equal parts $\mathrm{NH}_{4} \mathrm{OH}$ and $\mathrm{H}_{2} \mathrm{O}_{2}(3 \%) ; \times 100$.

\begin{tabular}{|c|c|c|c|}
\hline & \multicolumn{2}{|c|}{ Test } & \multirow{2}{*}{ Remarks } \\
\hline & Temperature & Creep rate & \\
\hline B & $\begin{array}{l}{ }^{\circ} \mathrm{F} \\
250 \\
250 \\
250 \\
300 \\
300 \\
300\end{array}$ & $\begin{array}{l}\% / 1000 h r \\
19.7 \\
19.7 \\
2.98 \\
2.64 \\
180 \\
18.5\end{array}$ & $\begin{array}{l}\text { Structure at fracture. } \\
\text { Same specimen as A; structure at "rim" surface. } \\
\text { Structure } 0.05 \text { in. from complete fracture. } \\
\text { Do. } \\
\text { Structure corresponding to deformation at beginning of third stage. } \\
\text { Do. }\end{array}$ \\
\hline
\end{tabular}




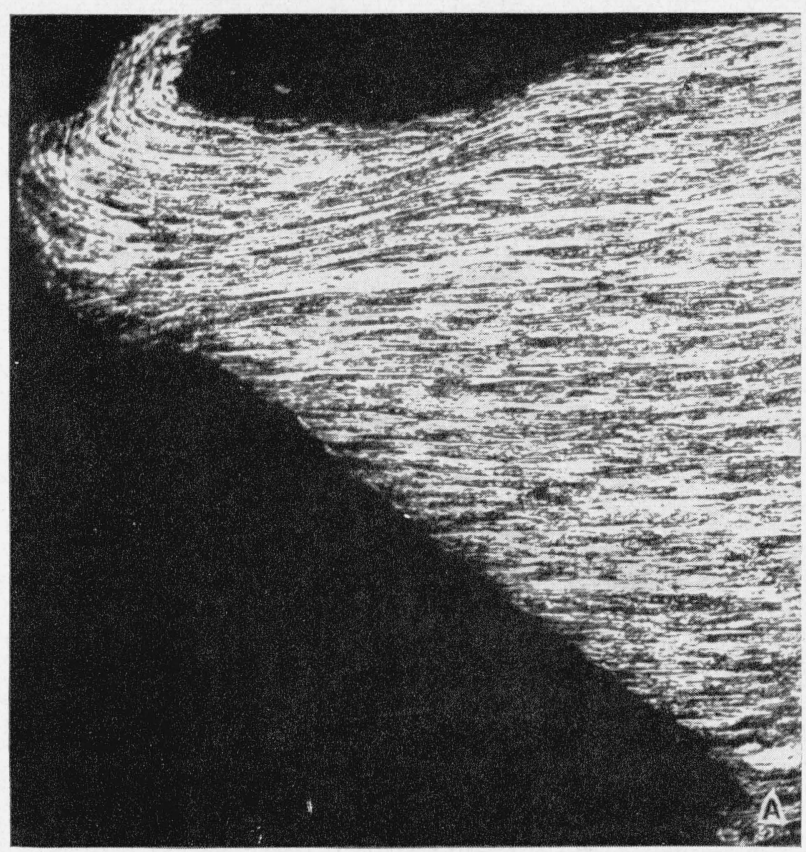

es

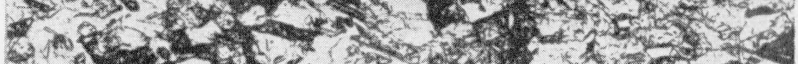

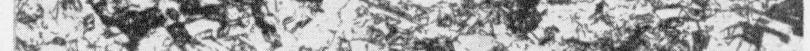

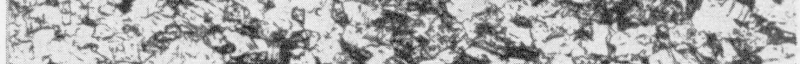

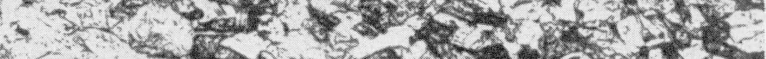

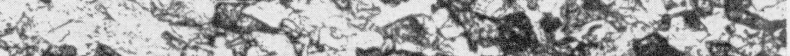

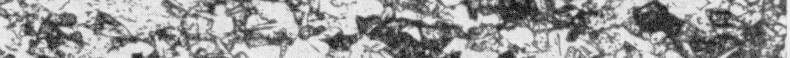

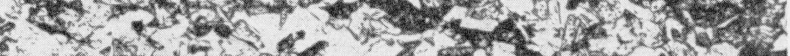

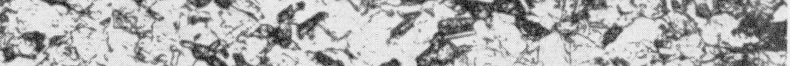

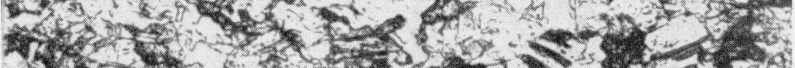

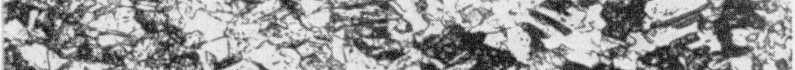

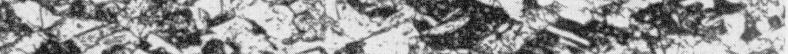
7. CE

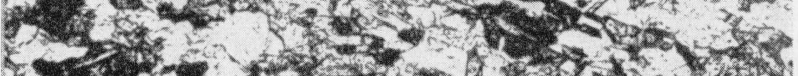

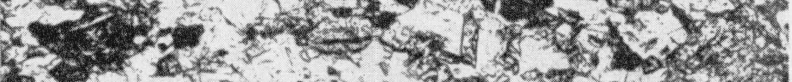

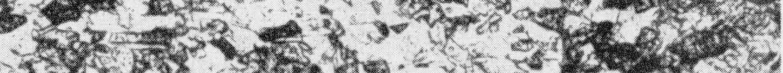

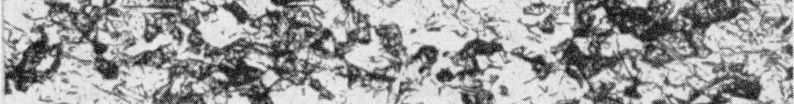

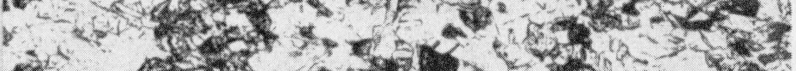

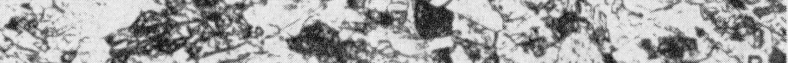
$7^{\circ}$ J
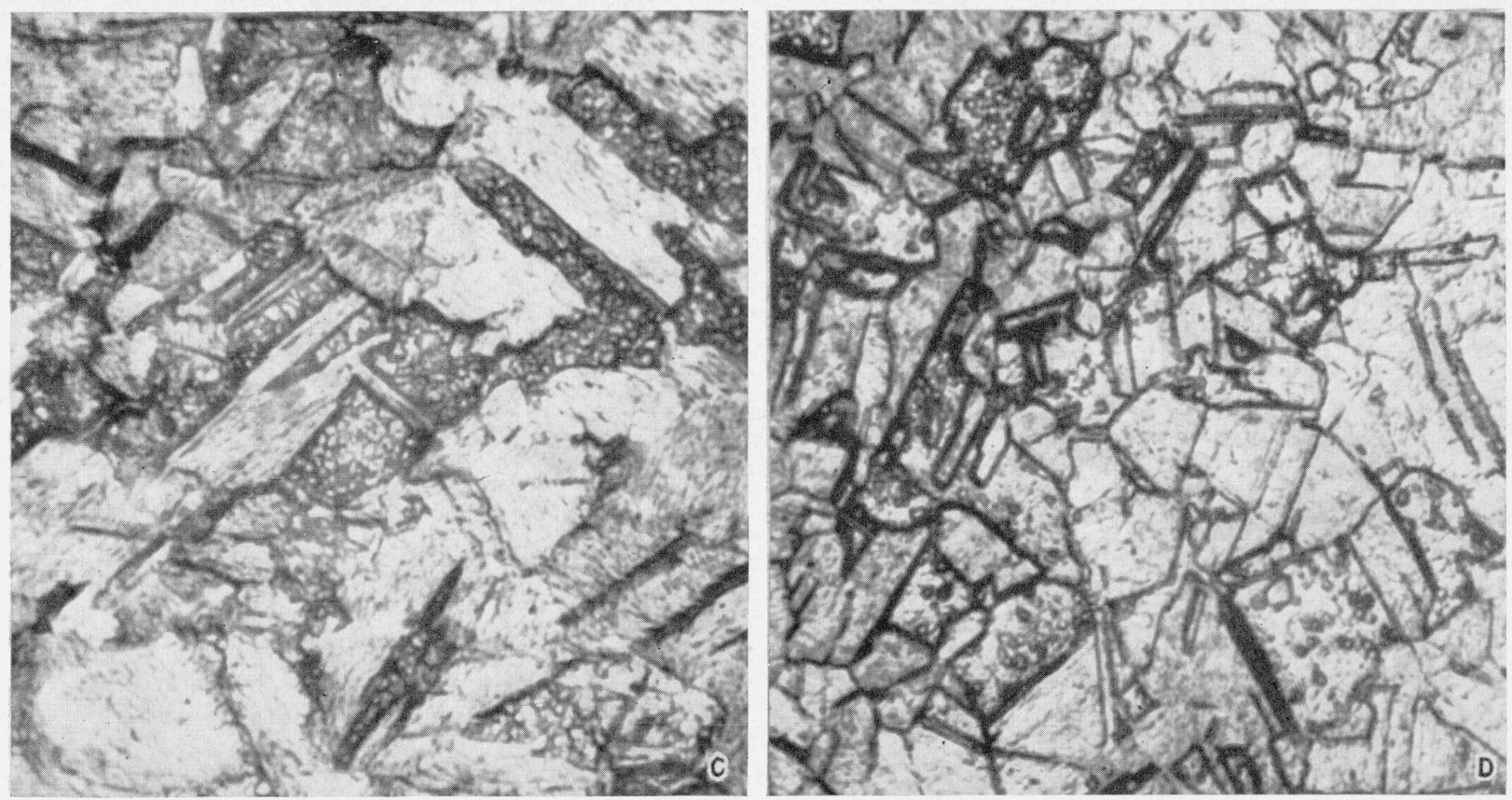

FIGURE 25. Effect of temperature and rate on structure of copper initially as annealed.

Longitudinal sections $\mathrm{A}$ and $\mathrm{B}$ etched in equal parts $\mathrm{NH}_{4} \mathrm{OH}$ and $\mathrm{H}_{2} \mathrm{O}_{2}(3 \%)$. Longitudinal section $\mathrm{C}$ and transverse section $\mathrm{D}$ etched in 3.5 parts glacia acetic acid, 4.5 parts nitric acid (conc.) and 2 parts ethylene glycol.

\begin{tabular}{|c|c|c|c|}
\hline & \multicolumn{2}{|c|}{ Test } & \multirow{2}{*}{ Remarks } \\
\hline & Temperature & Creep rate & \\
\hline B & $\begin{array}{l}{ }^{\circ} F \\
110 \\
300 \\
300 \\
\\
\\
300\end{array}$ & $\begin{array}{l}\% / 1000 \mathrm{hr} \\
35 \\
1.0(\mathrm{a}) \\
24.5(\mathrm{~b}) \\
1.0 \\
24.5 \\
1.0 \\
24.5\end{array}$ & $\begin{array}{l}\times 100 \text {; structure at "rim" of fractured surface. } \\
\times 100 \text {; (a) } 16,000 \text { psi for } 3,000 \mathrm{hr} ; \text { (b) } 20,800 \mathrm{psi} \text { for } 193 \mathrm{hr} \text {; structure at } \\
22.5 \text {-percent extension. } \\
\times 750 \text {; same specimen as B; longitudinal section. } \\
\times 750 \text {; same specimen as B; transverse section. }\end{array}$ \\
\hline
\end{tabular}



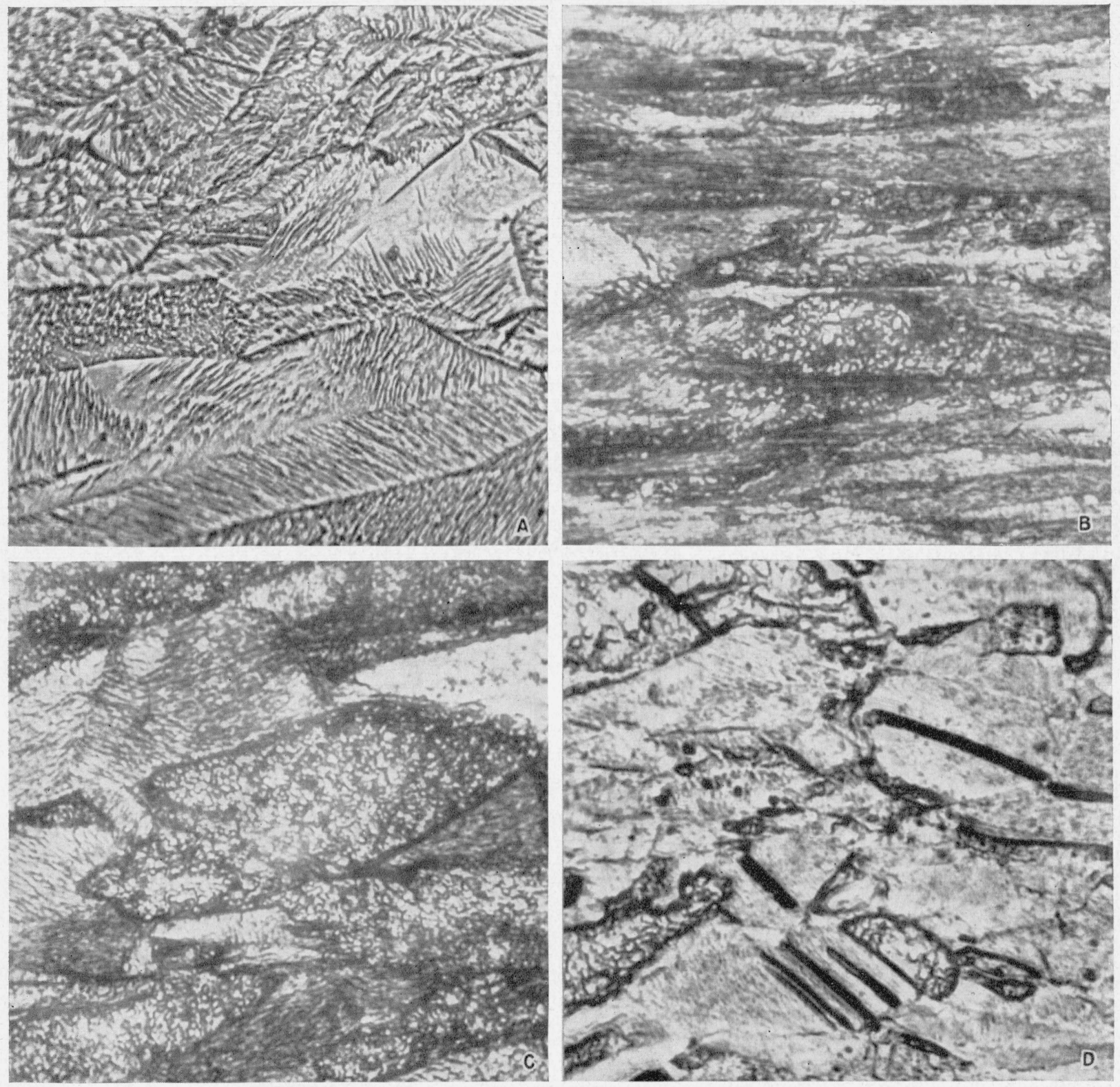

FIGURE 26. Effect of testing conditions on the structure of copper initially as cold-drawn 40-percent reduction of area.

Longitudinal sections etched in 3.5 parts glacial acetic acid, 4.5 parts nitric acid (cone.), and 2 parts ethylene glycol, $\times 750$.

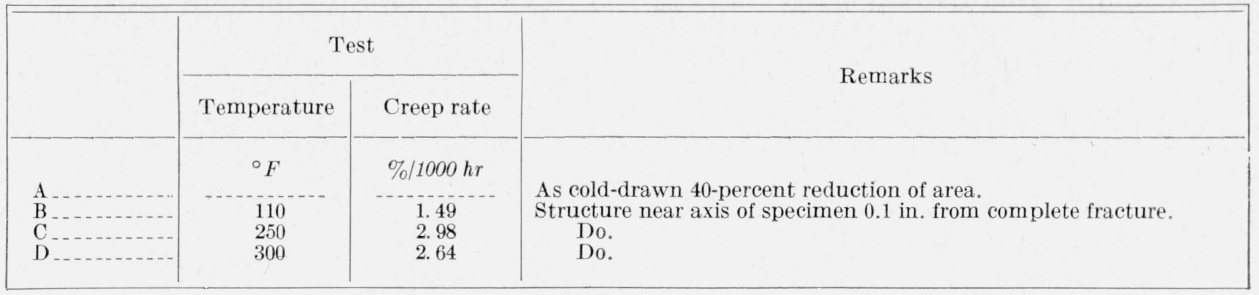



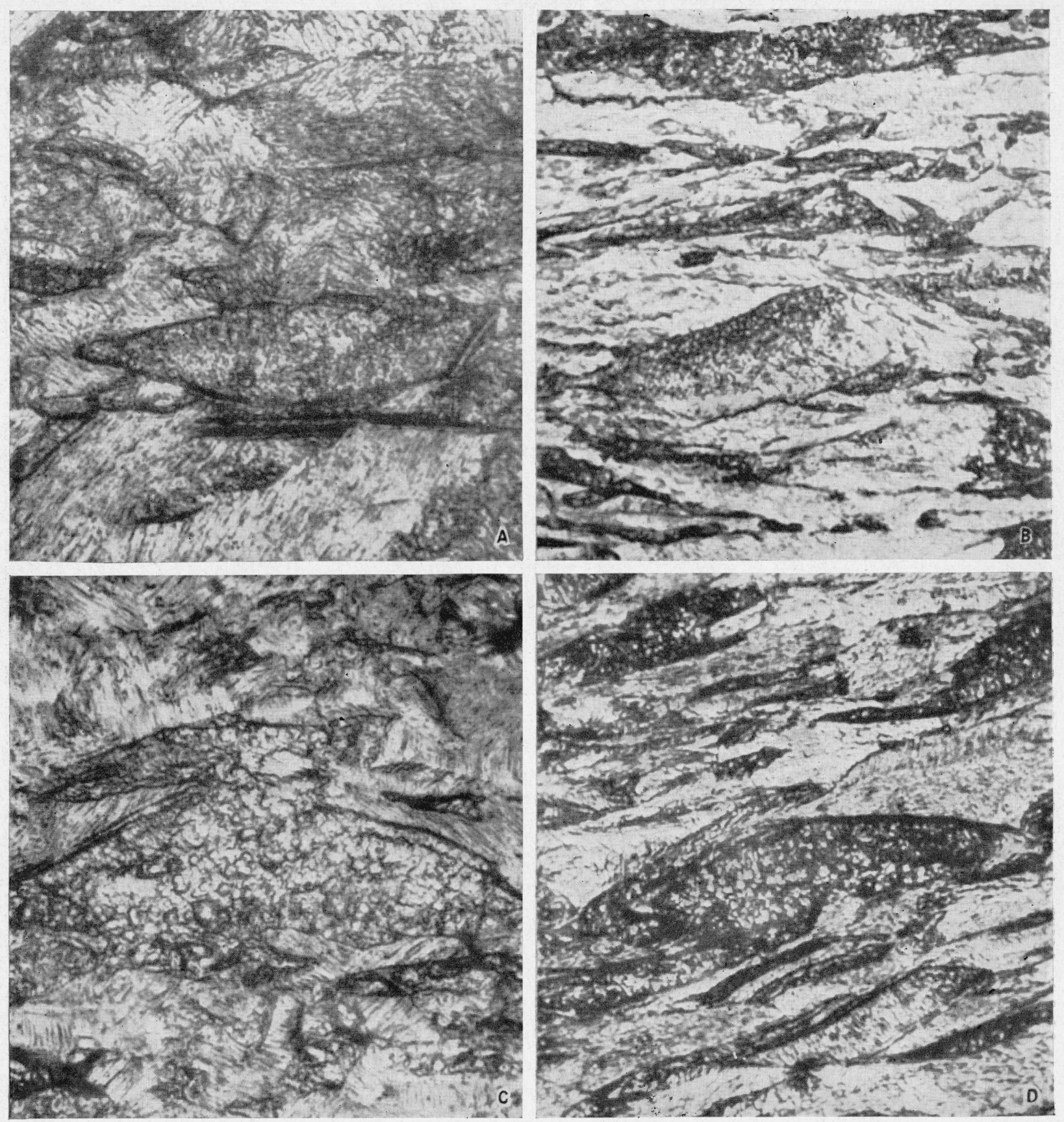

FIGURE 27. Effect of testing conditions and plastic deformation on structure of copper initially as cold-drawn 40-percent reduction of area.

Longitudinal sections etched in 3.5 parts glacial acetic acid, 4.5 parts nitric acid (conc.), and 2 parts ethylene glycol, $\times 750$.

\begin{tabular}{|c|c|c|c|}
\hline & \multicolumn{2}{|c|}{ Test } & \multirow{2}{*}{ Remarks } \\
\hline & Temperature & Creep rate & \\
\hline $\begin{array}{l}\mathrm{A} \\
\mathrm{B} \\
\mathrm{C} \\
\mathrm{D}\end{array}$ & $\begin{array}{l}-F \\
3 J 0 \\
300 \\
300 \\
110\end{array}$ & $\begin{array}{c}\% / 1000 \mathrm{hr} \\
18.5 \\
180 \\
18.5 \\
1.49\end{array}$ & $\begin{array}{l}\text { Structure at axis } 0.1 \mathrm{in} \text {. from position of complete fracture. } \\
\text { Do. } \\
\text { Same specimen as A; structure at axis } 0.2 \text { in. from position of com- } \\
\text { plete fracture. } \\
\text { Structure at axis } 0.2 \mathrm{in} \text {. from position of complete fracture. }\end{array}$ \\
\hline
\end{tabular}


The effect of rate of loading on creep characteristics was influenced by the prior thermal-mechanical history of the copper.

The resistance to creep at all the temperatures used was increased by cold-drawing the copper prior to testing. This superiority in creep properties was more evident at relatively low than at high temperatures and creep rates. Plastic extension at the beginning of the third stage and at fracture was greater for the annealed than for the cold-drawn copper, but the reduction of area values at fracture were similar.

Conformance to existing theories of transient flow (first stage) was found only in a limited number of cases, as the form of the extension-time curve in the first stage of creep was dependent on the applied stress and the test temperature.

Discontinuous flow was evidenced in each of the stages of creep and was found to be dependent on the test conditions, prior thermal-mechanical history, and stage of test.

The general trend was for the fracture stress to increase as the true strain at fracture increased. Fracture stress at equal strain value was materially increased by prior cold-drawing.

Increase in creep rate or decrease in test temperature generally caused an increase in hardness at room temperature.

The degree of necking; the tendency toward the formation of a rim at fracture; the tendency toward transcrystalline separation of the parent grains; the absence of cracks in regions away from complete fracture; the number and prominence of strain markings; and the tendency toward formation of subcrystals of smaller size as a result of plastic deformation; all increase with decrease in test temperature or increase in creep rate.

Cold-drawing prior to the creep test appears to alter the region in which transcrystalline fracture occurs. That is, transcrystalline fracture predominates at higher temperatures and lower creep rates for the cold-drawn than for the annealed copper. Furthermore, for similar test conditions, the size and number of subcrystals evident in the grains after the creep tests are decreased by cold-drawing the copper prior to testing in creep.

The authors are indebted to C. R. Johnson for assistance in this investigation.

\section{References}

[1] W. D. Jenkins and T. G. Digges, Creep of high-purity copper, J. Research NBS 45, 153 (1950) RP2121.

[2] W. D. Jenkins and T. G. Digges, Influence of strain rate and temperature on the creep of cold-drawn ingot iron, J. Research NBS 43, 117 (1949) RP2013.

[3] H. Burghoff and C. H. Mathewson, Time and temperature effects in the deformation of brass crystals, Trans. Am. Inst. Mining Met. Engr. (Inst. of Metals Div.) 143, 45 (1941)

[4] A. H. Cottrell and V. Aytekin, The flow of zine under constant stress, J. Inst. Metals 78, 389 (July 1950).

[5] E. N. da C. Andrade, The creep of metals, Report of a conference on the strength of solids, The Physical Society, page 20 (1948).

[6] N. F. Mott and F. R. N. Nabarro, Dislocation theory and transient creep, Report of a conference on the strength of solids, The Physical Society, page 1 (1948).

[7] W. D. Jenkins, Creep of high-purity aluminum, J. Research NBS 46, 310 (1950) RP2201.

Washington, April 3, 1951. 